Nowaczyk, N. (2021): Redeposition experiments with natural sediments from the SE Black Sea in magnetic fields between about 2 and $114 \mu \mathrm{T}$. Geophysical Journal International, 224, 1, 271-289.

https://doi.org/10.1093/gji/ggaa455 


\title{
Redeposition experiments with natural sediments from the SE Black Sea in magnetic fields between about 2 and $114 \mu \mathrm{T}$
}

\author{
Norbert R. Nowaczyk ${ }^{\oplus}$ \\ Helmoltz Centre Potsdam GFZ German Research Centre for Geosciences, Climate Dyanamics and Landscape Evolution, Telegrafenberg, 14473 Potsdam, \\ Germany.E-mail: Norbert.Nowaczyk@gfz-potsdam.de
}

Accepted 2020 September 23. Received 2020 September 21; in original form 2020 April 27

\begin{abstract}
S UMMAR Y
Diluted slurry with an initial density of $1.30 \mathrm{~g} \mathrm{~cm}^{-3}$ prepared from natural glacial Black Sea sediments was deposited under controlled field conditions between 1.72 and $114.21 \mu \mathrm{T}$. Compaction was achieved by evaporation of a portion of the pore water from the open sample boxes over 4-7 d until a density of about $1.44-1.55 \mathrm{~g} \mathrm{~cm}^{-3}$ was reached. Magnetizations $\mathbf{M}$ acquired in a magnetic field $\mathbf{B}$ follow a slightly non-linear function with $\mathbf{M} \sim \mathbf{B}^{0.82}$. Similar relationships were also obtained for palaeointensity estimates for the artificial samples by using normalization by low-field susceptibility, anhysteretic remanent magnetization and saturation magnetization. All samples are characterized by a magnetic fabric typical for natural sediments as checked by determining the anisotropy of magnetic susceptibility. The sediments' anisotropy is in the range of 6-7 per cent and it is characterized by an oblate anisotropy ellipsoid with its small axis perpendicular to the deposition plane. According to scanning electron microscope imaging low-Ti magnetite particles present in the used sediments are in the range of 1-30 $\mu \mathrm{m}$ with the majority of particles $2-5 \mu \mathrm{m}$ in size. Obtained results confirm the conclusion from other magnetostratigraphic studies that the Laschamps geomagnetic polarity excursion in the Black Sea area exhibited field values as low as $2.8 \mu \mathrm{T}$ in its transitional phase between normal and reversed polarity.
\end{abstract}

Key words: Magnetic properties; Geomagnetic excursions; Magnetic fabrics and anisotropy; Palaeointensity; Palaeomagnetism.

\section{INTRODUCTION}

Magnetostratigraphic investigations of marine and lacustrine sediments have provided a lot of detailed information about temporal as well as spatial variations of the geomagnetic field throughout the geological past. Therefore, it is important to know how sediments acquire their magnetization. In the past about $70 \mathrm{yr}$ several redeposition studies of various types of artificial and natural sediments were performed in order to test their ability to properly record (relative) changes in geomagnetic field strength (e.g. Johnson et al. 1948; Irving \& Major 1964; Kent 1973; Løvlie 1976; Barton et al. 1980; Tucker 1980, 1981; Otofuji \& Sasajima 1981; Tauxe \& Kent 1984; Yoshida \& Katsura 1985; Tauxe 1993, van Vreumingen 1993a,b; Katari \& Tauxe 2000; Katari et al. 2000; Gilder et al. 2019). Several studies found a non-linear relationship between an acquired magnetization and the applied field (Fig. 1). However, this nonlinearity takes place only at fields higher than about $50 \mu \mathrm{T}$ (Yoshida \& Katsura 1985) to $100 \mu \mathrm{T}$, with highest fields applied of up to about $1000 \mu \mathrm{T}$ (Johnson et al. 1948; Barton et al. 1980). In these studies, towards the maximum field applied, the acquired magnetizations seem to reach a saturation, that is, with increasing field more and more particles become completely aligned so that no further magnetization can be acquired. Theoretically, going to low field amplitudes, it might be possible that below a certain threshold level no magnetization at all is acquired. It could also be possible that the acquired magnetization is an underestimation of the field present during deposition, due to friction inhibiting a proper alignment of magnetic particles inside the sediment matrix.

\subsection{Motivation of the study}

The analyses of sediment cores recovered from the SE Black Sea yielded a fairly large amplitude range in the record of relative palaeointensity (Nowaczyk et al. 2013). By comparison to results from absolute palaeointensity investigations, the obtained Black Sea relative palaeointensity data were recalculated into absolute field values (Liu et al. 2020). For the N-R-transition of the Laschamps excursion (Bonhommet \& Babkine 1967; Gillot et al. 1979; Guillou et al. 2004; Plenier et al. 2007; Nowaczyk et al. 2012; Kornprobst \& Lénat 2019) at $41.3 \mathrm{ka}$ a field amplitude as low as $2.8 \mu \mathrm{T}$ was calculated, whereas at around $50 \mathrm{ka}$ field intensities of $60 \mu \mathrm{T}$ prevailed. The present-day field 


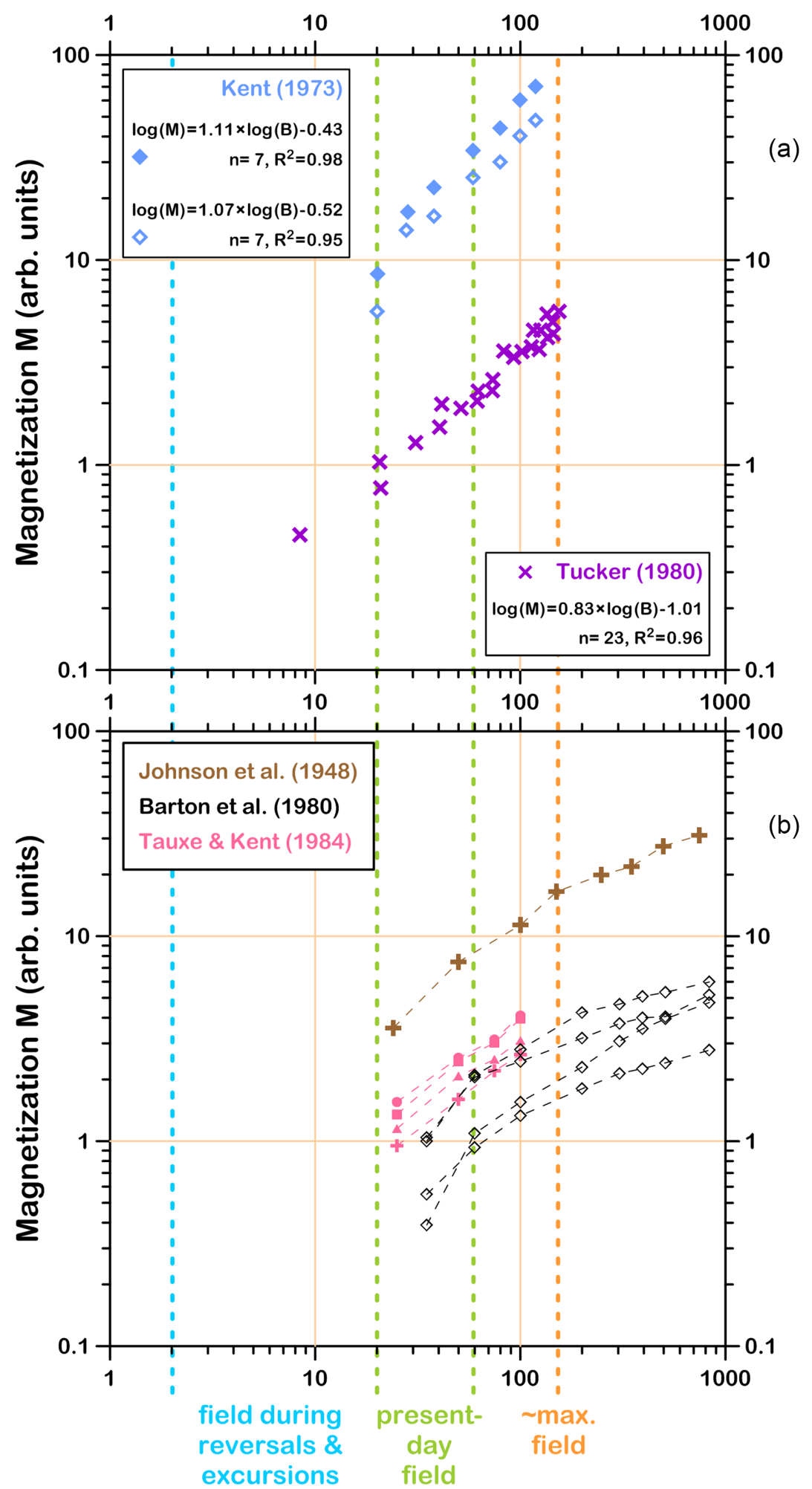

Figure 1. Overview of some published redeposition experiments to check the acquisition of a detrital remanent magnetization (DRM) in sediments shown in double-log plots. Most of the experiments only cover the range of present-day field intensities $(\sim 20-70 \mu \mathrm{T}$; bracketed by green dashed lines) to about twice of the present-day field maximum (marked by an orange dashed line), which was probably reached 3 ka ago in the Near-East (Shaar et al. 2018). For this field range (apparently) a more or less linear relationship between field during deposition and the acquired magnetization could be found as plotted with linear axes in the original publications. At higher fields, due to an increasing number of particles getting completely aligned to the applied field, the acquired magnetization approaches a saturation value (e.g. Johnson et al. 1948, brown crosses; Barton et al. 1980, black open diamonds). From these studies there are just a few data available for the acquisition of a DRM at low fields of down to $2 \mu \mathrm{T}$ ( $\sim 10$ per cent of today's lowest field, marked by a blue dashed line), as expected for the geomagnetic field during reversals and excursion. This time interval is the major subject of this study. 
in the SE Black Sea is $48.9 \mu$ T (A.D. 2020; WMM 2019-2024, https://www.ngdc.noaa.gov/geomag-web/?model = igrf). Thus, a ratio of about 24:1 between highest and lowest field intensities during marine isotope stage (MIS) 3 was determined. Some palaeointensity stacks (see Nowaczyk et al. 2013, and references therein) yielded much lower dynamic ranges, with the lowest of only $4: 1$ (e.g. PISO1500, Channell et al. 2009) for the same time window. Therefore, the question was raised whether the studied depositional magnetization of SE Black Sea sediments reacted linearly to geomagnetic field variations, or not (Nowaczyk et al. 2013, 2018). If they did, palaeointensity stacks showing a much lower dynamic range have to be treated with caution since it has to be assumed that they reflect time series significantly damped in amplitude. If the studied Black Sea sediments did not linearly record geomagnetic field intensities it has to be found out how this non-linearity can be defined.

Experimental data from samples prepared in fields lower than $100 \mu \mathrm{T}$, plotted with linear field and magnetization axes, were interpreted by, for example Kent (1973) and Tucker (1980), to reflect an approximate linear relationship. When data is plotted in a doublelog plot (Fig. 1a), and fitted with:

$\log (\mathbf{M})=\mathbf{a} \cdot \log (\mathbf{B})+\mathbf{c}$

actually, a strict linear relationship is only given when the slope $\mathbf{a}$ is equal to 1 , since eq. (1) is equivalent to:

$\mathbf{M}=\mathbf{c} \cdot \mathbf{B}^{\mathbf{a}}$

with the factor comprising influences by, for example magnetic concentration in the sediment. Although the data from Kent (1973) and Tucker (1980) plot along a straight line also in the double$\log$ plot, the relationship between determined magnetization and magnetic field is not strictly linear, since the slopes are around 1.10 and 0.83 , respectively (Fig. 1). Anyway, the field range between 0 and $40 \mu \mathrm{T}$ was covered only by 3 data points, lowest applied field $20 \mu \mathrm{T}$ (Kent 1973), or 4 data points, lowest applied field $8 \mu \mathrm{T}$ (Tucker 1980). Thus, a focused check for a potential nonlinearity with respect to low fields has not been studied in detail yet. Therefore, in this study, a special focus was set on the remanence acquisition in low fields. The range between 1.72 and $114.21 \mu \mathrm{T}$ was studied in detail in order to check whether an underestimation of the applied field by the acquired magnetization occurs, or not. This would then clarify the question whether the dynamic range in the determined (relative) palaeointensities obtained from Black Sea sediments are an artefact, or an expression of real geomagnetic field variability.

\section{MATERIAL AND METHODS}

\subsection{Properties of collected material}

For the redeposition experiment of this study natural sediment material was collected when cleaning palaeomagnetic samples taken from various sediment cores recovered from the SE Black Sea (e.g. Nowaczyk et al. 2012, 2013; Liu et al. 2018, 2019). Studied sediments comprise marine isotope stages (MIS) 1 to upper MIS 4 and (lower) MIS 5e to MIS 6, with a major erosive hiatus from $68 \mathrm{ka}$ back to about $120-130 \mathrm{ka}$, depending on site. Most of the Holocene and the lower Eemian (MIS 5e) sediments are built up of soft laminated dark green organic-rich marine sapropels and whitish coccolith oozes (partly not collected for this study), while the glacial sediments, deposited under freshwater lacustrine conditions, consist of mostly homogeneous fine grained organic-poor brownish to greyish siliciclastic material with variable amounts of calcium carbonate. There are no clear traces from bioturbation visible in the sediment cores but ostracods, which could be used for ${ }^{14} \mathrm{C}$ dating, are fairly abundant. They indicate oxic conditions during deposition. Glacial sediments from cooler phases in the Black sea area contain some ice rafted detritus (IRD), defined as particles $>125 \mu \mathrm{m}$ (Nowaczyk et al. 2012). Greigite $\left(\mathrm{Fe}_{3} \mathrm{~S}_{4}\right)$, found in some of the sediments, is unstable and quickly oxidizes into goethite $(\mathrm{FeOOH})$ when exposed to water and oxygen (Skinner et al. 1964). This was explicitly tested by keeping magnetically extracted greigite in an open beaker filled with water. After about two to three months only orange goethite was floating in the water. Since the material used for this study was kept under water in open beakers for years with frequent stirring it can be assumed that all greigite has vanished. Anyway, all glacial sediments were shown to be very homogenous with fairly constant mineral magnetic properties in terms of concentration, grain size and composition (Nowaczyk et al. 2012, 2013, 2018; Liu et al. 2018, 2019). Sedimentation rates in the glacials (MIS 2-4, MIS 6) were about 10 times higher than during the Holocene and the (lower) Eemian (Wegwerth et al. 2019; Liu et al. 2020; Nowaczyk et al. in prepration). Therefore, the sedimentary material collected for this study is by far dominated by the siliciclastic material from the glacials that have reproducibly recorded directional and intensity variations across the Laschamps (41.0 ka) and Mono Lake excursions (34.5 ka) in the very detail (Liu et al. 2020).

\subsection{Initial experiments}

Initial tests with incremental redeposition of dispersed sediment material performed inside a water column of $35 \mathrm{~cm}$ turned out to be not useful (Figs S1 and S2). A separation of the different grain size fractions occurred, resulting in clearly visible fining upward graded layers of 1-2 mm in thickness. Such sequences of graded layers are not seen in the studied natural sediments. Therefore, this way of redeposition was dismissed. In a next step, dispersed slurry was directly injected into standard palaeomagnetic boxes made from clear plastic with an internal size of $20 \times 20 \times 15 \mathrm{~mm}\left(6 \mathrm{~cm}^{3}\right)$, but still under water inside an $800 \mathrm{~cm}^{3}$ glass beaker. The resulting samples did not show a visible grain size grading but the slurry inside the boxes was mechanically too unstable to keep the acquired magnetization. As a compromise, it was decided to prepare a fairly thin slurry, sequentially inject it into the boxes, but placing these in air instead of under water. Thus, the liquid slurry could slowly loose pore water until it reached a pasty consistency about similar to natural sediments from the SE Black Sea. The precise procedure is explained in the next sections.

\subsection{Magnetic field control}

For the control/compensation of the ambient magnetic field a system of two nested pairs of rectangular and quadratic coils, respectively, was constructed (Fig. 2). A computer program was used to optimize the shapes and the number of windings of the coil pairs (Figs S3S7). Since it was initially intended to perform sedimentation in a small water column, the coils compensating the horizontal component $\mathrm{H}$ were vertically extended. Because of restricted place in the laboratory finally a pair of rectangular coils of $110.5 \times 80.5 \mathrm{~cm}$, a spacing of $52.2 \mathrm{~cm}$ and 48 windings per coil (horizontal compensation), and a pair of quadratic coils, with a size of $71.0 \times 71.0 \mathrm{~cm}$, 


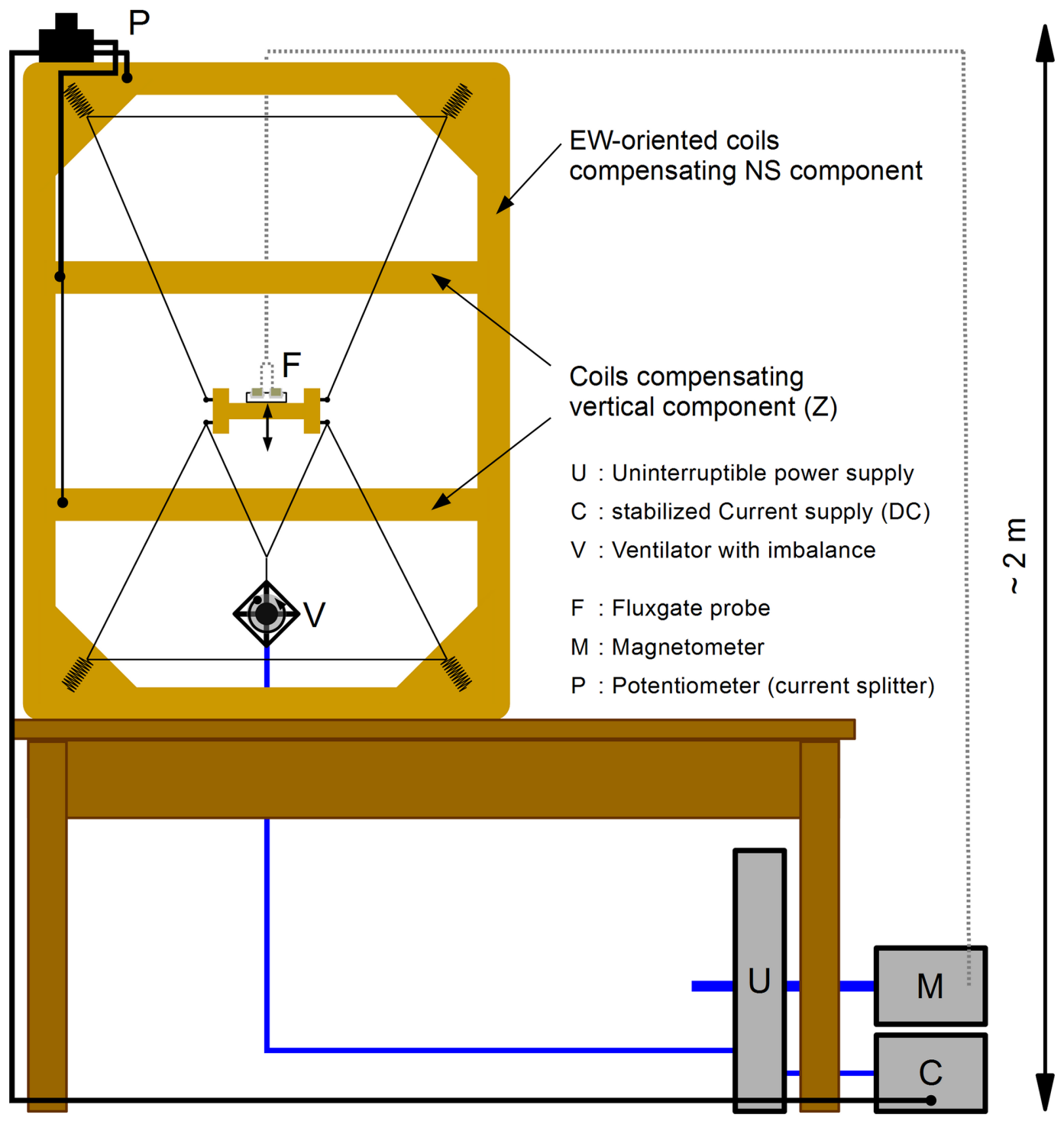

Figure 2. Sketch of the experimental setup for this study (for further details see Section 2.3; Figs S3-S7): A pair of vertically elongated rectangular coils, with their planes oriented magnetically EW, control the horizontal (NS) component, whereas a pair of square coils control the vertical component of the magnetic field. A stabilized current supply (C), connected to an uninterruptible power supply (UPS-U), is providing the current to the coil pairs via a potentiometer (P), splitting up the current, thus allowing some variations in field direction. A tri-axial fluxgate probe $(\mathrm{F})$ of a magnetometer $(\mathrm{M})$ is used to check the field intensity in three directions (NS, EW, vertical) when setting a field configuration with the power supply and the potentiometer. Prior to the DRM acquisition experiment the fluxgate probe is removed. A wooden platform in the coil system's centre is held in position by strings which in turn are connected to the coils' frame by springs, allowing the platform to vibrate. Vibration is excited by an old ventilator (V) hanging below the platform, with an imbalance glued off-axis to its rotating part. It is also connected to the UPS. A wooden frame placed onto the platform is holding seven plastic boxes (see Fig. 3) for taking up diluted slurry.

a spacing of $41.0 \mathrm{~cm}$, and 80 windings per coil (vertical compensation) were built. The coil system yields a (theoretical) compensation volume with a height of about $30 \mathrm{~cm}$ and a diameter of about $15 \mathrm{~cm}$ with a compensation better than 1 per cent (Figs S4 and S5). The whole coil system was oriented magnetically EW so that only a single pair of coils for compensation of the horizontal field component $\mathrm{H}$ was needed. Thus, only two pairs of coils were necessary to be able to (under-/over-)compensate the ambient magnetic field vector completely. The obtained geometry factors (resistances) are $178 \mu \mathrm{T}$ $\mathrm{A}^{-1}(10.2 \mathrm{Ohm})$ for the vertical $(\mathrm{Z})$ compensation and $82.3 \mu \mathrm{T} \mathrm{A}^{-1}$ $(8.31 \mathrm{Ohm})$ for the horizontal $(\mathrm{H})$ compensation. Prior to construction, field values of $Z=45.2 \mu \mathrm{T}$ and $H=18.3 \mu \mathrm{T}$ were measured in the laboratory. Thus, almost equal compensation currents of 0.255 A for the vertical $(Z)$ and 0.222 A for the horizontal $(Z)$ component are required (Fig. S6). This led to a further simplification of the compensation system using a single high-precision stabilized power supply (TTi QL355P, precision $1 \mathrm{~mA}$ ) and a $10 \mathrm{Ohm}$ $(60 \mathrm{~W})$ wire-potentiometer to split up the current for the two coils.

A wooden platform of about $15 \times 18 \mathrm{~cm}$ was constructed to take up the sample boxes for sedimentation. It is centred inside the coil system by $1-\mathrm{mm}$-thick Aramid (Kevlar) strings which in turn are held by eight springs mounted to the edges of the coil frame (Figs 2 and S7). Thus, the sample platform can be put at variable heights and it is able to vibrate, if excited. It was assumed that keeping the injected slurry under vibration might promote its compaction by expelling water out of the pore spaces, and/or might promote an easier alignment of the magnetic particles within the slurry. In order to excite vibration a small ventilator was hang below the platform (Fig. 2). Its nominal rotation frequency is in the range of $2500 \mathrm{rpm}$, 
or about $42 \mathrm{~Hz}$. An imbalance by gluing a small peace of metal onto the ventilator off axis forced a vibration that was transmitted to the sedimentation platform via the strings that were used to hang the ventilator below the platform. A small wooden holder was constructed to take up seven sample boxes closely packed in order to expose them to similar field conditions in the coils' centre. During the deposition experiments the sample boxes' $X$-axes were always oriented towards NW (Fig. 3).

\subsection{Field settings}

In order to have well defined conditions, clearly different from the ambient field, the coils' fields were mostly oriented anti-parallel to the magnetic field in the laboratory. This overcompensation required a total current (power) of up to $1.0 \mathrm{~A}(10 \mathrm{~W})$, splitted into $0.5 \mathrm{~A}$ per coil pair by the potentiometer (Figs 2 and S6). Due to the coils' and power supply's specifications, respectively, no higher currents could be used this way, yielding a field of about $70 \mu \mathrm{T}$ opposite to the ambient field. For higher field settings only the vertical component connected directly to the power supply was used providing fields of up to $-114.21 \mu \mathrm{T}$ (vertically up).

The field in the coils' centre was adjusted prior to each deposition experiment using an Applied Physics Systems (APS) 520A tri-axial fluxgate magnetometer. Further on, it was assumed that the field is sufficiently kept at a constant value by the stabilized power supply. In order to be prepared for short power failures, potentially spoiling the results from the long-term deposition experiments, power supply and ventilator both were secured by an uninterruptible power supply. At the end of one (the beginning of a new) deposition experiment, the field setting was checked again. In general, the field was the same in the range of $\pm 0.05 \mu \mathrm{T}$.

\subsection{Estimation of evaporation rate}

In order to check how fast the prepared slurry looses pore water a few evaporation tests were performed in advance. Palaeomagnetic boxes were filled completely with diluted slurry (density $\sim 1.35 \mathrm{~g} \mathrm{~cm}^{-3}$ ) and then placed on a precision balance (OHAUS ANALYTICAL Plus, Type AP 110 S), capable of measuring weights of up to $100 \mathrm{~g}$ with a precision of $0.1 \mathrm{mg}$. One test sample was weighed every minute in the first phase, but normally, weight determination was performed over $4-5 \mathrm{~d}$, with $2-3$ readings per day (morning, noon and afternoon) only. Between the readings the test sample was left on a table covered with a plastic beaker placed upside-down above the test sample but held up by other four empty sample boxes around to enable some ventilation. Some other samples were stored without cover between the measurements, monitoring the maximum evaporation possible under normal laboratory conditions.

\subsection{Sample preparation for remanence acquisition}

For the main experiments, mixed Black Sea sediment (details see Section 2.1) was diluted by distilled water and stirred with a household mixer for homogenization. It was kept in a reservoir of about $800 \mathrm{~cm}^{3}$, covered with plastic foil. It was also kept at a more or less constant density of $1.30( \pm 0.02) \mathrm{g} \mathrm{cm}^{-3}$ by checking its density in regular intervals (three to four times a week), and adding distilled water when needed. The slurry was fairly liquid, that is, it was able to flow and to form a (fairly) flat surface, but thick enough to prevent separation of coarser from finer material even under vibration. For sample preparation the sample boxes were placed on the wooden platform in the centre of the field-controlling coils.

For injection of the slurry into the sample boxes $5 \mathrm{~cm}^{3}$ syringes were used. The sediment was picked up by sucking it into a syringe out of the upper portion of the slurry kept inside the about $12 \mathrm{~cm}$ high $800 \mathrm{~cm}^{3}$ reservoir beaker. Thus, it could be avoided to pick up eventually present little stones (IRD), assuming they have collect at the beaker's bottom. Before each injection, the slurry was again virulently stirred for homogenization for about $30 \mathrm{~s}$ using the household mixer. For the first sets of samples with vibrating platform, over one week, amounts of $1.5-2.5 \mathrm{~cm}^{3}$ were injected into the seven boxes each morning and/or late afternoon. After each injection of the slurry, the boxes were shortly and carefully shaken by hand to completely equalize the slurry's surfaces. Between the injections the samples were left open in order to evaporate a certain amount of pore water for condensing the slurry. In the first phase of this kind of experiments, the boxes were covered by one large plastic box (further details are listed in Table 1) in order to suppress evaporation. By this procedure, after a total settling time $t_{\mathrm{S}}$ of $168 \mathrm{hr}(7 \mathrm{~d})$ a total amount of $\sim 11.5 \mathrm{~cm}^{3}$ of slurry could be injected into the $6 \mathrm{~cm}^{3}$ sample boxes. In the second phase of these experiments, the settling time $t_{\mathrm{S}}$ was reduced to $96 \mathrm{hr}(4 \mathrm{~d})$ with slightly larger portions of slurry being injected into the boxes. Furthermore, the sample boxes were kept completely open to achieve a faster compaction by evaporation (details listed in Table 2). In both preparation schemes the slurry inside the boxes lost about $5.5 \mathrm{~cm}^{3}$ of water. It was then still wet with a pasty consistency but already stiff enough for performing the various measurements, partly needing to turn the samples upside down (see Section 2.7). At the end of each deposition experiment, the weights of the samples, with the boxes now closed by their lids, were measured. The density of the condensed sediment was determined by subtracting the weight of closed empty boxes $(2.8 \mathrm{~g})$ and then dividing by its internal volume $\left(6 \mathrm{~cm}^{3}\right)$. In general, after measurement of all parameters, the slurry was removed from the boxes and put back into the $800 \mathrm{~cm}^{3}$ reservoir. The loss of water in the recycled slurry was compensated by adding the amount of water that was lost by evaporation during the experiments. The empty boxes were disposed since they might have taken up a remanence during magnetization acquisition experiments (Section 2.7). These types of experiments yielding 42 sets of seven samples each were performed over a total time interval of 20 months.

In a third experimental phase, for another collection of sample sets, an even shorter scheme was used according to the details given in Table 3. The major difference to phases 1 (7-d experiments) and 2 (4-d experiments) was that the platform was not vibrating during settlement of the slurry. The major goal was to check the (un-)importance of vibration during settlement/condensing of the slurry. Only after injection of the slurry, like in experimental phases 1 and 2, the boxes were shortly shaken by hand to equalize the slurry's surfaces. The injection of a total of $10 \mathrm{~cm}^{3}$ of slurry was accomplished after $48 \mathrm{hr}(2 \mathrm{~d})$, allowing the production of two sample sets at different fields per week. During these experiments the slurry inside the boxes lost about $4 \mathrm{~cm}^{3}$ of water per sample. Production of the thirteen sets of samples produced this way was accomplished in 2 months.

For testing the speed of lock-in, a single set of seven samples was treated in a special way. Only the vertical component was changed to $Z=-81.12 \mu \mathrm{T}$ (up). In the morning, with the vibration of the platform turn on, the boxes were completely filled with $6.5 \mathrm{~cm}^{3}$ of slurry. Thus, the slurry inside the boxes was domed up a little bit. After $5 \mathrm{hr}$ and $25 \mathrm{~min}$ of condensing by evaporation, the boxes were 


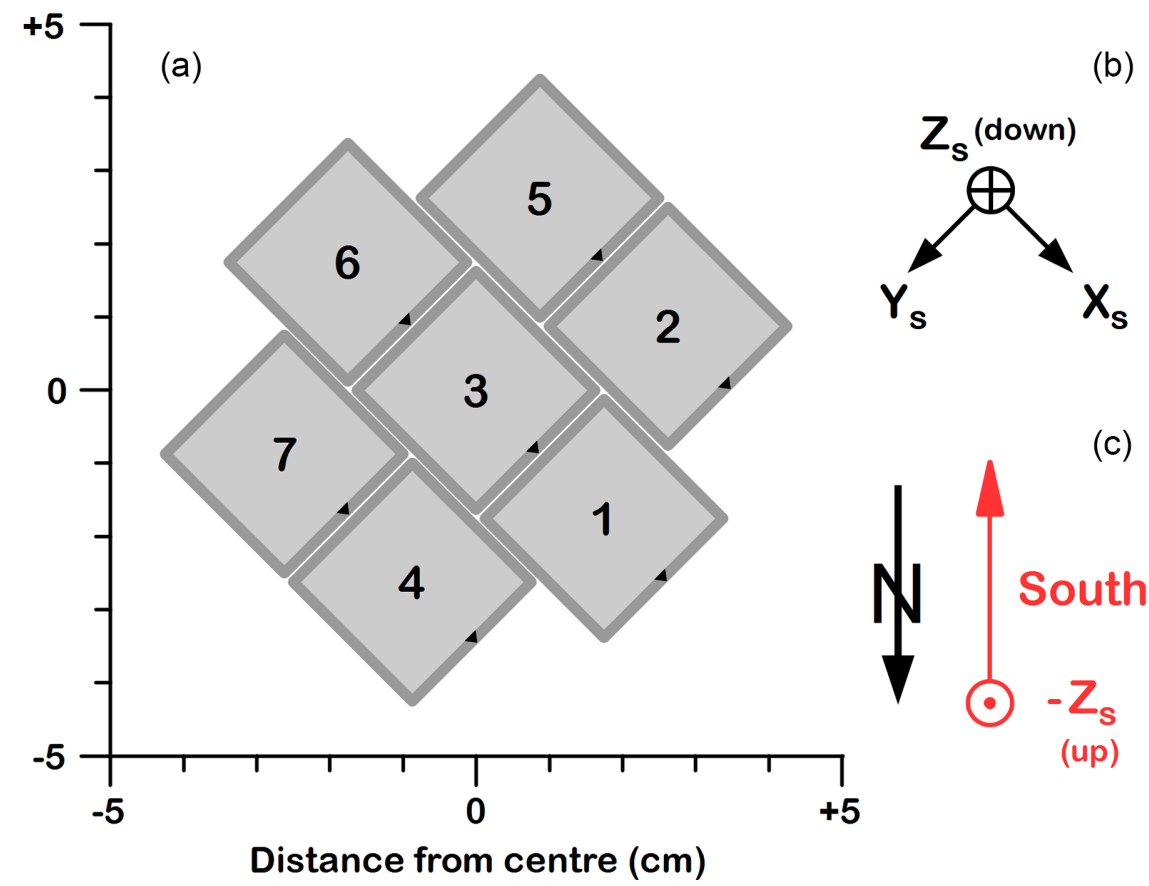

Figure 3. Sketch of the seven plastic boxes (a) placed in the centre of the coil system (Figs 2 and S7). The samples' coordinate system (b) is rotated by $45^{\circ}$ with respect to the geographic coordinate system (c). All seven samples are sited within a radius of less than $5 \mathrm{~cm}$ around the coils' centres where by theoretical calculations the field set by the current supply is varying by not more than 1 per cent. In general, for the DRM acquisition experiments the field was oriented upward and Southward (red arrows in c).

Table 1. Initial preparation scheme of a data set with a settling time of 168 $\mathrm{hr}$ and vibrating platform, yielding one set of seven samples per week. The total amount of injected slurry calculates to $10.5-11.5 \mathrm{~cm}^{3}$. From morning to late afternoon the samples were loosely covered by a large plastic box. Overnight and during the weekends the samples were tightly covered by a large plastic box.

\begin{tabular}{lcc}
\hline Day of the week & Morning & Late afternoon \\
\hline Monday & $2.0 \mathrm{~cm}^{3}$ & $2.0 \mathrm{~cm}^{3}$ \\
Tuesday & $2.0 \mathrm{~cm}^{3}$ & $1.5-2.0 \mathrm{~cm}^{3}$ \\
Wednesday & - & $1.0 \mathrm{~cm}^{3}$ \\
Thursday & $1.0-1.5 \mathrm{~cm}^{3}$ & - \\
Friday & $1.0-1.5 \mathrm{~cm}^{3}$ & - \\
Saturday & - & - \\
Sunday & - & - \\
Monday & Measurements & \\
\hline
\end{tabular}

Table 2. Optimized preparation scheme of major data set with a settling time of $96 \mathrm{hr}$ and vibrating platform, yielding one set of seven samples per week. The total amount of injected slurry calculates to $11.5 \mathrm{~cm}^{3}$. The samples were not covered enabling maximum evaporation.

\begin{tabular}{lcc}
\hline Day of the week & Morning & Late afternoon \\
\hline Monday & $2.0 \mathrm{~cm}^{3}$ & $2.5 \mathrm{~cm}^{3}$ \\
Tuesday & $2.0 \mathrm{~cm}^{3}$ & $2.0 \mathrm{~cm}^{3}$ \\
Wednesday & - & $1.5 \mathrm{~cm}^{3}$ \\
Thursday & - & $1.5 \mathrm{~cm}^{3}$ \\
Friday & Measurements & \\
\hline
\end{tabular}

closed with their lids to stop the evaporation process and also the current in the coil was turned off. The samples then were kept on the vibrating platform being exposed to the ambient field $(H=+18.3$ $\mu \mathrm{T}$, North; $Z=+45.2 \mu \mathrm{T}$, down) for further $116 \mathrm{hr}$ (almost $5 \mathrm{~d}$ ) before the samples were taken out for remanence measurements. A few similar experiments with other field settings (lower initial field
Table 3: Fast preparation scheme of a data set with a settling time of $48 \mathrm{hr}$ and still platform, yielding two sets of seven samples per week. The total amount of injected slurry calculates to $10.0 \mathrm{~cm}^{3}$. The samples were not covered enabling maximum evaporation.

\begin{tabular}{lcc}
\hline Day of the week & Morning & Late afternoon \\
\hline Monday & $2.5 \mathrm{~cm}^{3}$ & $3.0 \mathrm{~cm}^{3}$ \\
Tuesday & $2.5 \mathrm{~cm}^{3}$ & $2.0 \mathrm{~cm}^{3}$ \\
Wednesday & Measurements & \\
Wednesday & $2.5 \mathrm{~cm}^{3}$ & $3.0 \mathrm{~cm}^{3}$ \\
Thursday & $2.5 \mathrm{~cm}^{3}$ & $2.0 \mathrm{~cm}^{3}$ \\
Friday & Measurements & \\
\hline
\end{tabular}

amplitudes, shorter time interval under ambient field conditions) were also performed.

\subsection{Palaeo- and mineral magnetic measurements}

The artificial samples for this study were treated in a similar manner as the natural samples from Black Sea sediment cores (e.g. Nowaczyk et al. 2012; Liu et al. 2018). First, the anisotropy of magnetic susceptibility (AMS) was determined with an AGICO MultiFunction Kappabridge MFK-1S, applying a field of $200 \mathrm{mAm}^{-1}$ at a frequency of $976 \mathrm{~Hz}$. These measurements also provided the low field volume susceptibility $\left(\kappa_{\mathrm{LF}}\right)$. Obtained orientations and magnitudes of the main axes of the AMS ellipsoid $\left(K_{\max }, K_{\text {int }}, K_{\min }\right)$ were used to evaluate the magnetic fabric of the artificially produced samples.

The acquired detrital/depositional remanent magnetization (DRM) of the artificial samples was measured and demagnetized using $2 \mathrm{G}$ Enterprises superconducting long-core rock magnetometers, a 2G755SRM (replaced by a 2G755-4K in summer 2019) with in-line tri-axial alternating field (AF) demagnetizer and automatic 
sample handler for 8 (9) discrete samples. A 2G600 single-axis demagnetizer with an in-line coil for a static field was used to impart anhysteretic remanent magnetizations (ARM) with $100 \mathrm{mT}$ AF amplitude superimposed by static fields of $50 \mu \mathrm{T}$ (default) and $150 \mu \mathrm{T}$ (high-field experiments), respectively. The latter were imparted only on samples produced with vibrating platform and are termed in the following text as strong ARM (sARM). All DRMs and (s)ARMs were demagnetized in fields of 5, 10, 15, 20, 30, 40, 50, 65, 80 and $100 \mathrm{mT}$ AF peak amplitude. DRM demagnetization results were subjected to principal component analysis (Kirschvink 1980 ) in order to determine the characteristic remanent magnetization (ChRM). The slope of DRM intensity versus ARM intensity of common demagnetization steps was determined as a proxy for the relative 'palaeointensity', as it was done for the natural sediment samples (e.g. Nowaczyk et al. 2013). Thus, results from this common approximation could be linked directly to the amplitude of the measured field applied during the deposition/condensing experiments. The magneto-mineralogical homogeneity of the sediment material used in the deposition experiments was controlled by monitoring standard rock magnetic parameters and their ratios. The anhysteretic susceptibility $\kappa($ ARM $)$, defined as the ARM intensity normalized by the static field used to impart the ARM, further normalized by the low-field magnetic susceptibility $\kappa_{\mathrm{LF}}\left(\kappa(\mathrm{ARM}) / \kappa_{\mathrm{LF}}\right)$ is indicative for magnetic grain size, with higher values indicating smaller grain sizes. The saturated isothermal remanent magnetization (SIRM) was determined after subjecting the samples to a pulsed field of $1.5 \mathrm{~T}$, and the $S$-ratio, by further applying a reversed field of 0.2 T to the acquired SIRM. The $S$-ratio is defined as:

$\mathbf{S}=\mathbf{0 . 5} \times\left(\mathbf{1}-\left[\mathbf{I R M}_{-0.2 \mathrm{~T}} / \mathbf{S I R M}_{1.5 \mathrm{~T}}\right]\right)$, with $0 \leq \mathrm{S} \leq 1$.

The $S$-ratio is close to 0 (1) for high-coercivity (low-coercivity) minerals such as hematite (magnetite, greigite). The ARM/SIRM ratio, like the $\kappa(\mathrm{ARM}) / \kappa_{\mathrm{LF}}$ ratio, can be used in mono-mineralic assemblages (preferably magnetites) as a proxy for relative grain size changes since the ARM activates mostly finer particles whereas the SIRM is acquired by particles of all grain sizes. For the studied natural Black Sea sediments the consultation of the SIRM $/ \kappa_{\mathrm{LF}}$ ratio turned out to be helpful to distinguish greigite- from magnetitebearing samples (Nowaczyk et al. 2012, 2013). Magnetite-bearing sediments yielded SIRM $/ \kappa_{\mathrm{LF}}$ ratios of about $10 \mathrm{kAm}^{-1}$, or lower, whereas increasing greigite contents increased this ratio up to about $100 \mathrm{kAm}^{-1}$ (then mostly dominated by greigite).

In order to directly check the grain size of magnetic particles in the slurry used for the experiments a magnetic extract according to the methods described in Nowaczyk (2011) was inspected in a Carl Zeiss SMT Ultra 55 Plus Scanning Electron Microscope (SEM) with an option for energy-dispersive X-ray spectroscopy (EDS) analysis. Samples were inspected at a distance of about $9 \mathrm{~mm}$ with an electron beam accelerated by $20 \mathrm{kV}$, using an aperture of $120 \mu \mathrm{m}$ (because of EDS analyses), with images taken in the backscatter mode in order to highlight the heavy element-bearing minerals such as magnetite.

\section{RESULTS}

Within the frame of this study a total of 390 samples in groups of seven samples each were deposited in fields ranging from 1.72 to $114.21 \mu \mathrm{T}$. The field values were chosen in a way that they are evenly distributed along a logarithmic field axis, thus yielding a preference for data related to low magnetic field values. The results from analytical procedures as applied normally to natural samples are discussed in the following sections.

\subsection{Evaporation rates}

At the beginning of the experiments, over seven to $10 \mathrm{~d}$, the decrease in water content by evaporation was tested by determining the weight of $6 \mathrm{~cm}^{3}$ sample boxes completely filled with diluted slurry. Samples completely uncovered lost about $1 \mathrm{~g}$ of water during the first $24 \mathrm{hr}$ through the open side of the boxes of $4 \mathrm{~cm}^{2}$, and about $0.5 \mathrm{~g}$ per day after five d (Fig. S8). Taking a split sediment core of $100 \mathrm{~cm}$ length and a diameter of $10 \mathrm{~cm}\left(\right.$ area $\left.=1000 \mathrm{~cm}^{2}\right)$ and an evaporation rate of $0.5 \mathrm{~g} \mathrm{~d}^{-1}$ through $4 \mathrm{~cm}^{2}$, a total loss of $125 \mathrm{~g}$ of water can be estimated if the core is kept uncovered for $24 \mathrm{hr}$. A general aspect that should be kept in mind when sampling sediment cores. Of course, evaporation depends on porosity and permeability which are different for the different types of sediment. A more or less constant loss of water in the range of $0.5 \mathrm{~g} \mathrm{~d}^{-1}$ was determined for samples that were kept under a large plastic box allowing some ventilation from the side (Fig. S8). These results provided the experimental framework conditions of the redeposition experiments.

\subsection{Magneto-mineralogy and imaging by SEM}

The determination of standard rock magnetic parameters determined for all investigated samples proved that the used slurry did not change significantly in composition or magnetic grain size throughout the duration of the experiments. The overall variation of grain-size indicative parameter ratios $\left(k(\mathrm{ARM}) / k_{\mathrm{LF}}, \mathrm{ARM} / \mathrm{SIRM}\right.$, $\left.\mathrm{SIRM} / k_{\mathrm{LF}}\right)$ is very small (Fig. S9). A mean $S$-ratio of $0.946( \pm 0.003)$ points towards some hematite present in the slurry.

Two images of a magnetic extract taken from the slurry used for the experiments are shown in Fig. 4. Nearly all (bright) grains visible in the images are low-Ti magnetites. The smallest ones are in the range of $1 \mu \mathrm{m}$ while the biggest ones are in the range of about $30 \mu \mathrm{m}$. However, the majority of grains is in the range of $2-5 \mu \mathrm{m}$, with a preference for an octahedral shape.

\subsection{Anisotropy of magnetic susceptibility}

Results from AMS determinations are shown in Figs 5 and 6. All samples are characterized by an oblate AMS ellipsoid (shape factor $<1)$. There is neither a clear trend in the shape factor of the AMS ellipsoid (Fig. 5a) nor in the AMS degree (Fig. 5b) versus magnetic field amplitude set during deposition of the samples. Only in the distribution of samples deposited with vibrating platform, towards higher fields, between about 50 and $100 \mu \mathrm{T}$, there is some apparent trend visible towards a more isotropic magnetic fabric with a lower AMS degree. This is not seen in the distribution of samples deposited with still platform, but their data base is much smaller. In total, the mean AMS degree for the latter set of samples is slightly lower (about 5 per cent, Fig. 5c) than for the larger data set of samples with vibrating platform (about 6 per cent, Fig. 5d). The lower AMS degree of samples produced on still platform is likely caused by the fact that also less material was injected into the sample boxes for condensing. This caused a lower density with less compaction of the slurry, and thus, a lower AMS degree at the and of the experiments. The mean density of samples from vibrating (still) plat form is $1.55( \pm 0.05) \mathrm{g} \mathrm{cm}^{-3}\left(1.44( \pm 0.03) \mathrm{g} \mathrm{cm}^{-3}\right)$. 

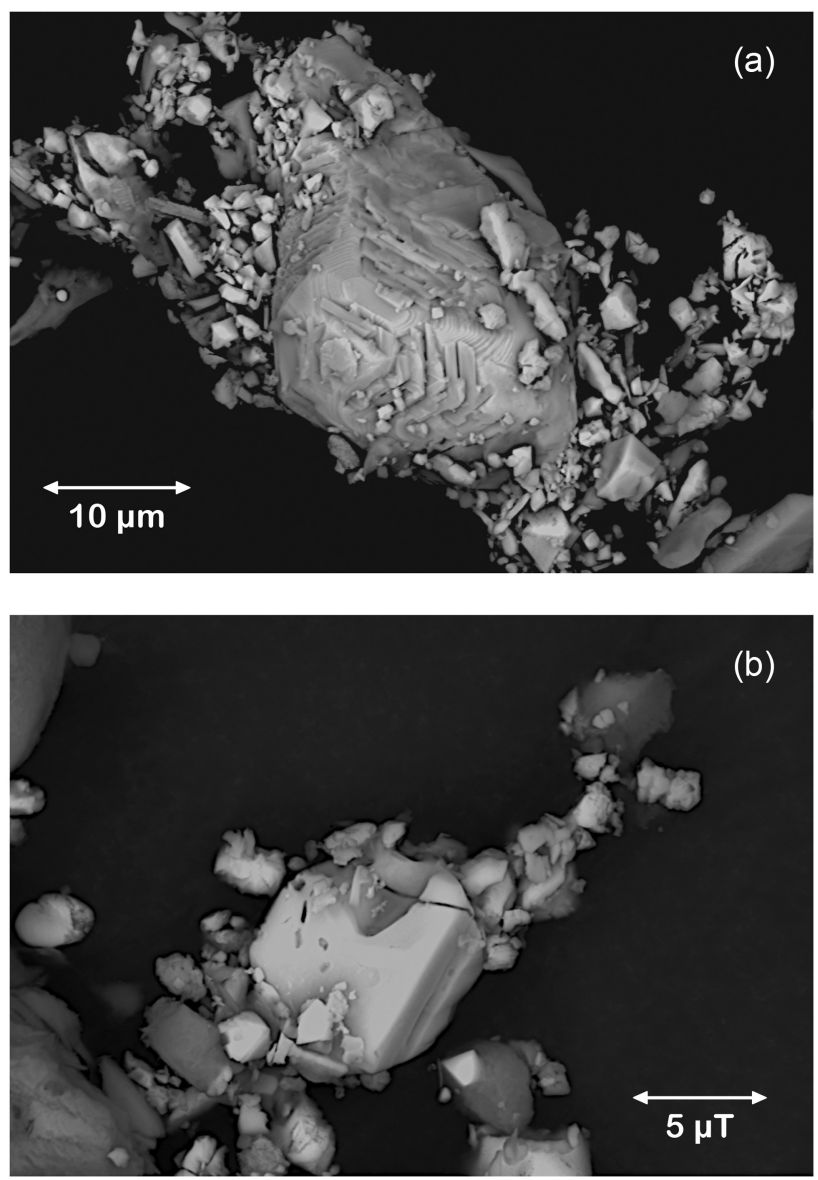

Figure 4. Scanning electron microscope (SEM) images of a magnetic extract from the slurry used for the DRM experiments. Generally, (titano-) magnetites in the range of $2-30 \mu \mathrm{m}$, with a preference for smaller grain sizes, could be observed. Images were taken in backscatter mode.

Besides the small difference in the AMS degree (Fig. 5; Figs 6b and d), both sample sets exhibit similar magnetic fabrics which is fairly comparable to natural undistorted sediment samples. Due to compaction in the vertical direction the short principle axis $K_{\min }$ is oriented strictly upward with inclinations of $I\left(K_{\min }\right) \leq 90^{\circ}$ (Figs 6a and c), showing only little scatter. This provides evidence that an appropriate method for producing artificial DRM samples similar to natural samples was applied.

\subsection{Alternating field (AF) demagnetization}

Vector endpoint diagrams of AF demagnetization results from selected samples deposited in different field amplitudes (1.72-114.21 $\mu \mathrm{T})$ are shown in Fig. 7. All plots are in sample coordinates. Results are shown separately for variations in the horizontal $(X Y)$ plane (declination) and in a vertical $(H Z)$ plane (inclination), with red (blue) arrows marking the declination (inclination) of the magnetic field applied during deposition relative to the samples' coordinate axes. It is obvious that all samples deposited under standard conditions (Figs 7a, b, c, g, h and i) show a significant inclination shallowing, with the effect being somewhat larger at lower fields. An observation also done by King (1955) when performing redeposition experiments with homogenized varved silts from Sweden. Inclination shallowing actually is an indication that the magnetization is acquired fairly quickly after deposition with the direction shallowed by the subsequent compaction due to pore water evaporation in vertical direction only, such as observed by Blow \& Hamilton (1978). The associated mean volume reduction in the vertical direction, estimated from the amount of injected material of $11.5 \mathrm{~cm}^{3}(10.0$ $\mathrm{cm}^{3}$ ) and the volume of the final sample of $6 \mathrm{~cm}^{3}$, is in the range of 48 per cent (40 per cent) for samples deposited on vibrating (still) platform.

Fig. 8 shows the simplified concept for the interpretation of the AF demagnetization results. For reasons of clarity only four injections are discussed. With the first injection the box gets filled by about one third and the slurry quickly acquires a magnetization parallel to the test field (Fig. 8a). Since compaction caused by evaporation of pore water can occur only in vertical direction only the vertical component of the remanence vector shrinks according to the compaction. This introduces the inclination shallowing, illustrated by the light and dark red arrows in Fig. 8(b). After some time, for example half a day, the slurry is condensed enough and fills only one quarter of the box (Fig. 8b). Then the second layer gets injected and it also acquires quickly a magnetization parallel to the test field and starts to shrink due to evaporation (Fig. 8c). It also inhibits evaporation from the layer below, injected before. The same happens when the third and fourth layer, respectively, have been injected (Fig. 8d). Thus, when the magnetization is acquired quickly after injection (case 1 in Fig. 8e) the inclination shallowing is proportional to the degree of compaction (downward directed arrows in Fig. 8e). The final direction is then parallel to the dark red arrow in Fig. 8e. If the magnetization is acquired after 50 per cent of achieved compaction (case 2 in Fig. 8e), the inclination shallowing is only half of the maximum shallowing (mid-red arrow). If the magnetization would be acquired only after the full degree of compaction is achieved no inclination shallowing would be observed (case 3 in Fig. 8e). In this case the magnetization (light red arrow) is parallel to the magnetic field B (black arrow in Fig. 8a). Since most of the produced samples show a significant shallowing it can be assumed that the magnetization was acquired in the very first phase of compaction forced by evaporation.

In order to further check the idea of a fast lock-in separate experiments with deviating conditions were performed (Figs 7d-f). In an upward directed field of $B=83.14 \mu \mathrm{T}\left(I=-77.35^{\circ}, D=45^{\circ}\right)$, $6.5 \mathrm{~cm}^{3}$ of slurry was injected into the plastic boxes placed on vibrating platform. After condensing for $5 \mathrm{hr}$ and $25 \mathrm{~min}$ the boxes were closed in order to stop further evaporation. To check whether a viscous component can develop, the samples were kept on vibrating platform for almost $5 \mathrm{~d}$, but with the coils' field turned off (Fig. 7f) so that the ambient field $\left(B=48.76 \mu \mathrm{T}, I=+67.96^{\circ}, D=45^{\circ}\right.$; in sample coordinates) could theoretically affect the samples further on. It was expected that this would realign at least a certain fraction of the magnetic grains parallel to the magnetic field now oriented downward but with same declination. However, only the initial field configuration with a steeply upward oriented vector can be seen in the AF demagnetization results (Fig. 7e). This finding also indicates that the magnetization was locked in completely soon after injection, but latest until the point when the coils' field was turned off (after $5 \mathrm{hr}$ ), since no contribution of the subsequently applied downward directed field can be seen in the vector endpoint diagrams. Two further experiments with initially upward-directed fields ( $I$ $=-59.04^{\circ}$ and $\left.-65.03^{\circ}\right)$ at lower intensities $(B=35.57$ and $43.35 \mu \mathrm{T}$ ) applied for about one day and subsequent exposure to the ambient field for about $2 \mathrm{~d}$ with vibrating platform were performed (results not shown). The analyses of their AF demagnetization data also did not show any evidence for a secondary vector component acquired parallel to the ambient field 

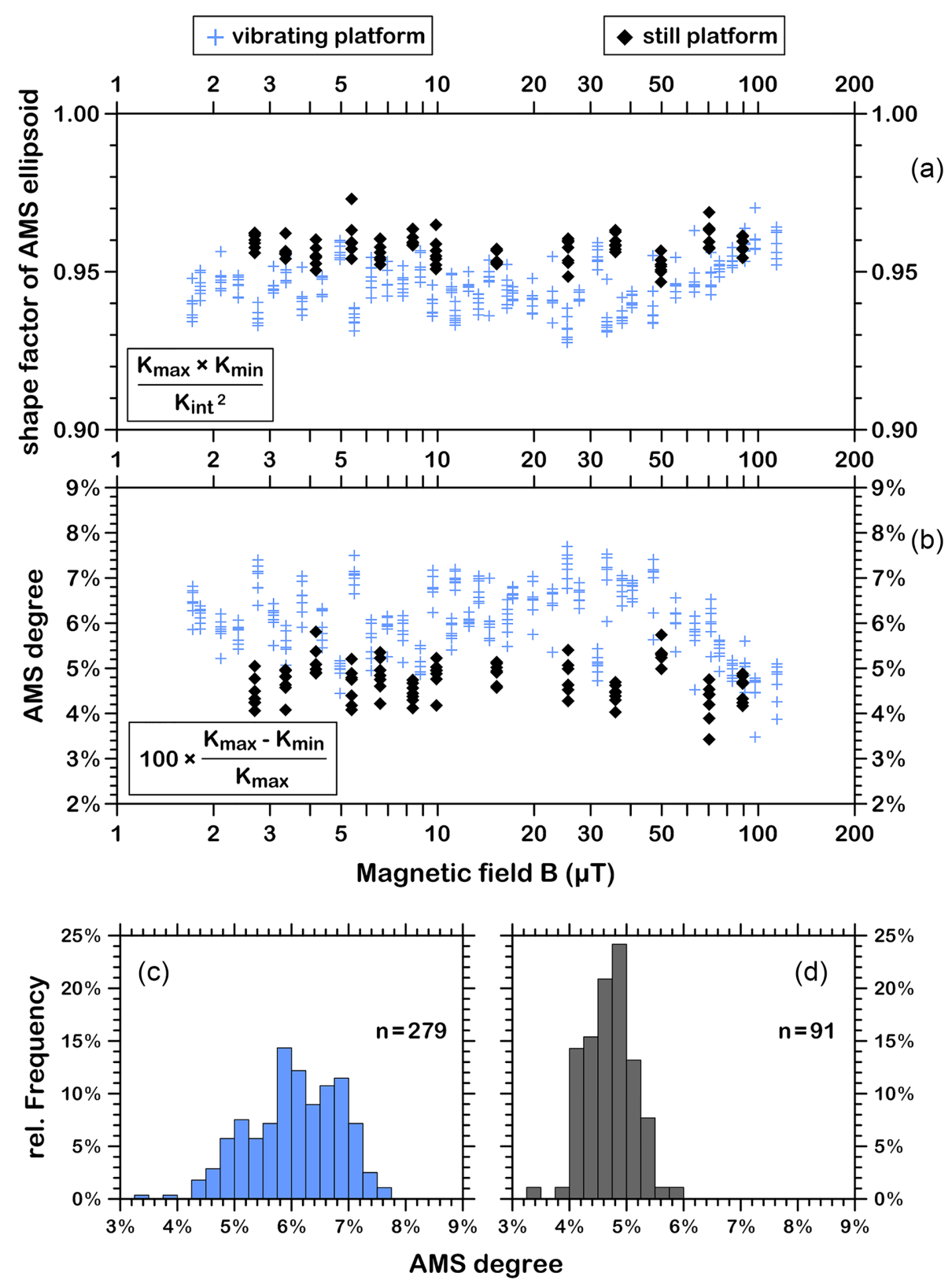

Figure 5. Results from magnetic fabric analyses by determinations of the anisotropy of magnetic susceptibility (AMS). The AMS shape factor (oblate $<1$, prolate $>1$ ) is shown in a) and the AMS degree is shown in b). Formulas for calculation of these parameters are given in the insets. The results are shown separately for samples produced with (without) vibration of the platform (Fig. 2) by blue crosses (black diamonds). $K_{\max }, K_{\text {int }}, K_{\min }-$ normalized principle axes of the AMS ellipsoid.

in the laboratory. These results actually led to the idea to produce a larger sample set completely without vibration of the sample platform. In general, their AF demagnetization results are undistinguishable from samples produced with vibrating platform (see Fig. 7).

The small experimental setup in a fairly busy palaeomagnetic laboratory had some limitations. Though the homogeneity of the compensated volume inside the coils was (theoretically) sufficient, magnetic field 'anomalies' produced by technical installations in the laboratory did not allow to set the magnetic field to values much lower than the minimum applied value of $1.72 \mu \mathrm{T}$ without larger gradients in intensity and/or direction across the space where the sample boxes were placed.

\subsection{Intensity of the acquired depositional remanent magnetization (DRM)}

Magnetization intensities acquired on vibrating and still platform, respectively, are shown separately in Fig. 9, both in linear and double-log diagrams. Intensities of individual samples are plotted with green open diamonds whereas mean values from seven samples deposited at the same field value are marked by black closed diamonds. The intensity values in the double-log diagram, with some scatter, plot along a straight line. Nonetheless, this result does not represent a linear behaviour of acquired DRM intensity versus magnetic field, since the slope of a linear function fitted to the data is not equal 1.00. Instead, the slope is $0.83(0.79)$ for samples deposited 


\section{vibrating platform}

(a)

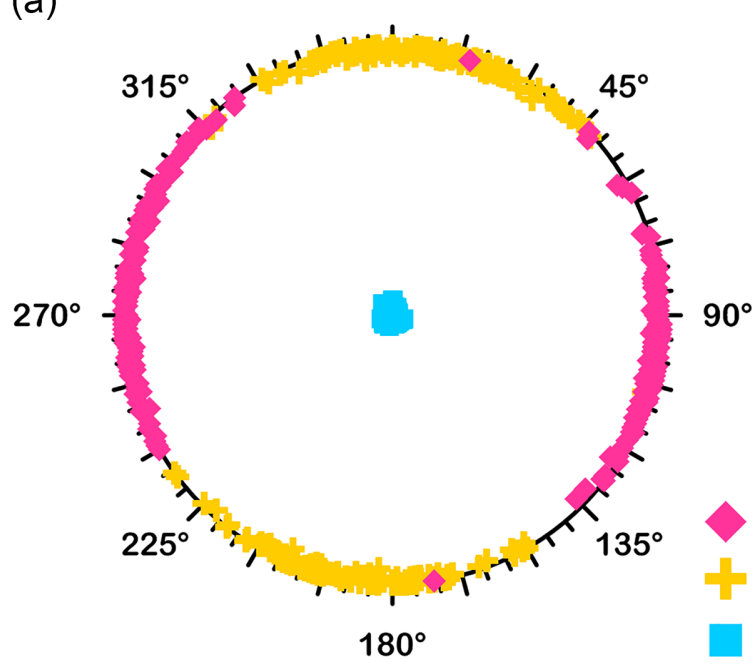

$0^{\circ}$ (b)

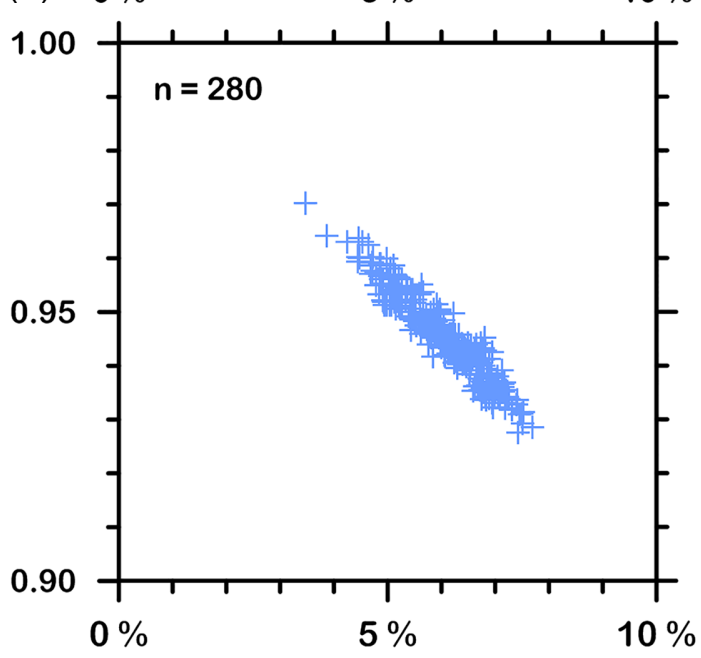

AMS degree

\section{still platform}

$0^{\circ}$

(c) on vibrating (still) platform (Fig. 9). This indicates a non-linear relationship $\left(\mathbf{M} \sim \mathbf{B}^{0.83} / \mathbf{B}^{0.79}\right)$, though not very much expressed. Since there are much less results from samples deposited on still platform their slightly more expressed non-linearity value is not interpreted as the effect of a (probably) slightly less efficient DRM acquisition.

\subsection{Estimation of 'relative palaeointensity' (rPI)}

Although the magnetic field during deposition of the samples is known by direction and intensity, typical palaeointensity estimates as applied to natural samples were determined as well. Bi-plots of DRM intensity versus intensity of the anhysteretic remanent magnetization (ARM; $50 \mu \mathrm{T}$ static, $100 \mathrm{mT}$ AF) throughout AF demagnetization are shown in Fig. 10. As recognized in data from natural Black Sea sediments samples (e.g. Nowaczyk et al. 2018; Fig. 6) a curved section, interpreted as the influence from viscous components of the remanence, can be seen at AF amplitudes, which turns into a straight segment at higher fields from about $40 \mathrm{mT}$ AF amplitude on (marked in black in Fig. 10). Estimates of relative palaeointensity were calculated from these straight segments by linear regression. Although the data cover almost two orders of magnitude in magnetic field intensity during deposition no significant difference in the shape of the curves can be seen in the diagrams of Fig. 10, maybe except for the one from the experiment with the lowest test field applied during deposition.

Summarized results from ARM-normalized rPI estimates together with DRM intensities normalized by low-field susceptibility 


\section{vibrating platform}
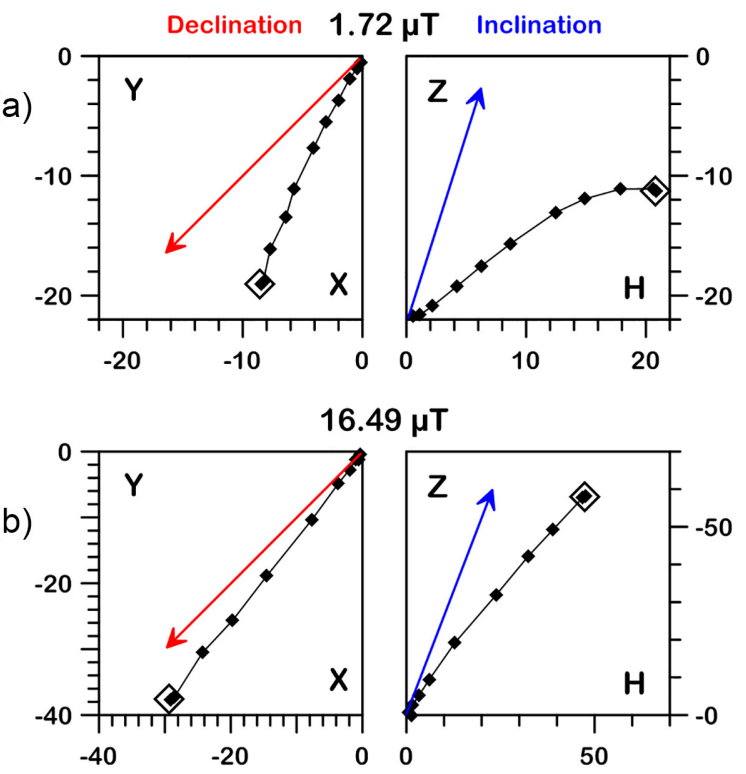

$16.49 \mu \mathrm{T}$

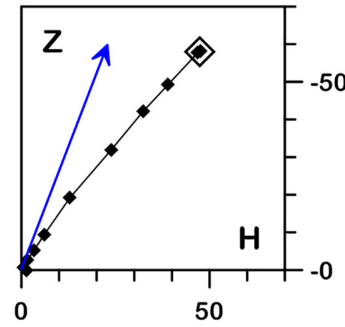

$114.21 \mu \mathrm{T}$

(c)
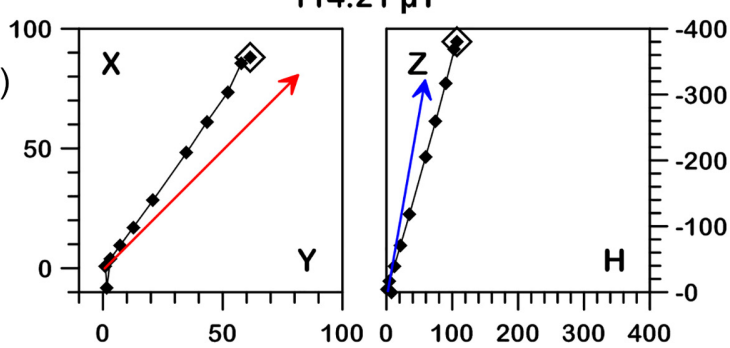

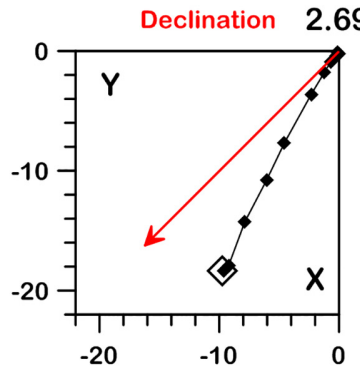

still platform
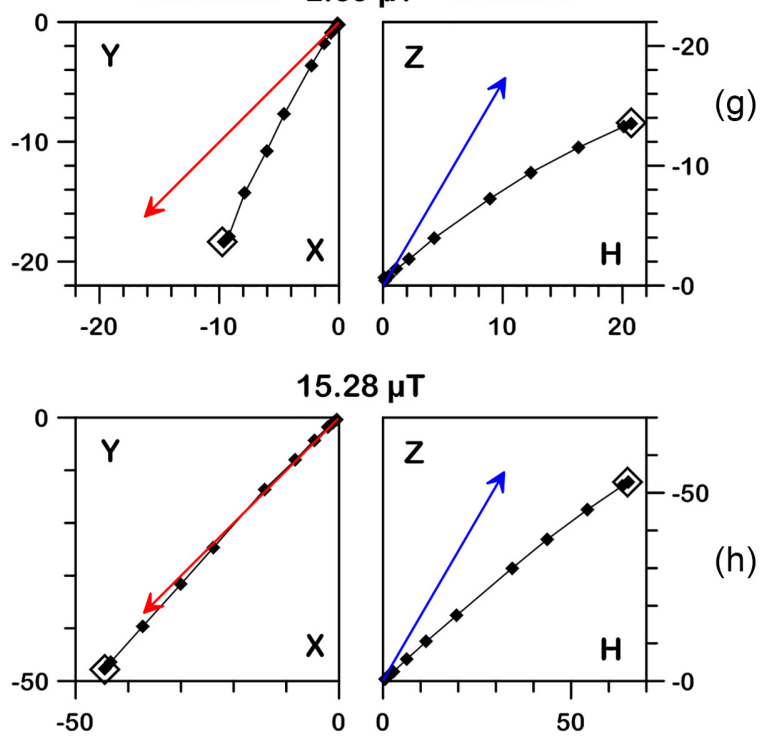

$89.38 \mu \mathrm{T}$

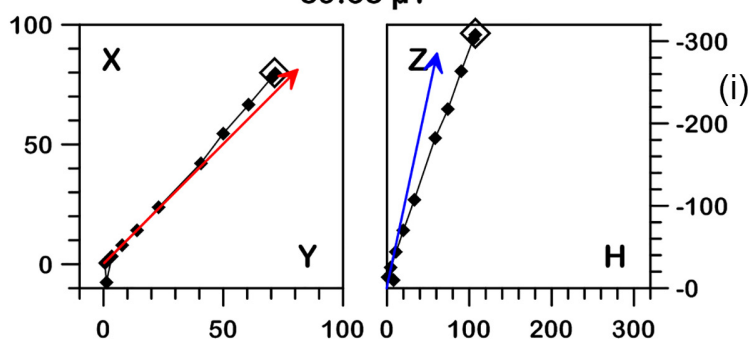

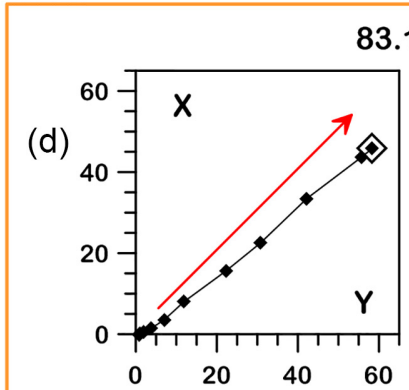

$83.14 \mu \mathrm{T}$

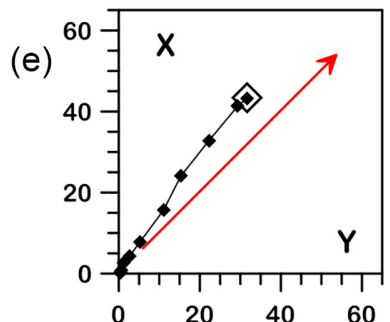

(f)

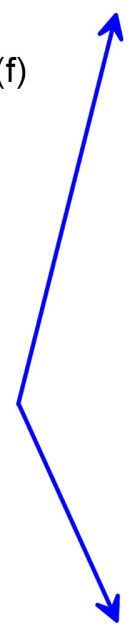

vibrating platform

Slurry in open boxes exposed to upward directed Field of $B=83.14 \mu \mathrm{T}$

Incl. $=-77.35$

for 5.42 hours

Slurry in closed boxes exposed to

downward directed (ambient) field of $B=48.76 \mu \mathrm{T}$ Incl. $=67.96^{\circ}$

for 116.12 hours

Figure 7. Results from alternating field (AF) demagnetization (0-100 mT in 11 steps, details see Section 2.7) of acquired DRMs for low (a, g), intermediate $(b, h)$ and high magnetic fields (c, i) during remanence acquisition, shown as vector endpoint diagrams. The respective test field amplitudes are given in $\mu \mathrm{T}$. The Zero-field AF step is marked by an open diamond and axis scaling of the diagrams is in $\mathrm{mAm}^{-1}$. Left (right): samples produced with vibrating (still) platform. For fields higher than $\sim 70 \mu \mathrm{T}$, only the vertical component could be inverted, yielding declinations (red arrows in XY plots) in sample coordinates (see Fig. 3) of $\sim 45^{\circ}$, whereas for lower fields the horizontal component was also inverted, yielding declinations of $225^{\circ}$. Inclinations of the fields set during the experiments are given by blue arrows in the HZ plots. $H=\operatorname{sqrt}\left(X^{2}+Y^{2}\right)$. In all results, inclinations of the acquired DRMs are clearly shallower than the inclinations measured with fluxgate probe at the beginning of each experiment. Demagnetization results from two samples (d, e) from a special magnetic viscosity experiment (f) are shown in the bottom (for more details see Section 2.5). 

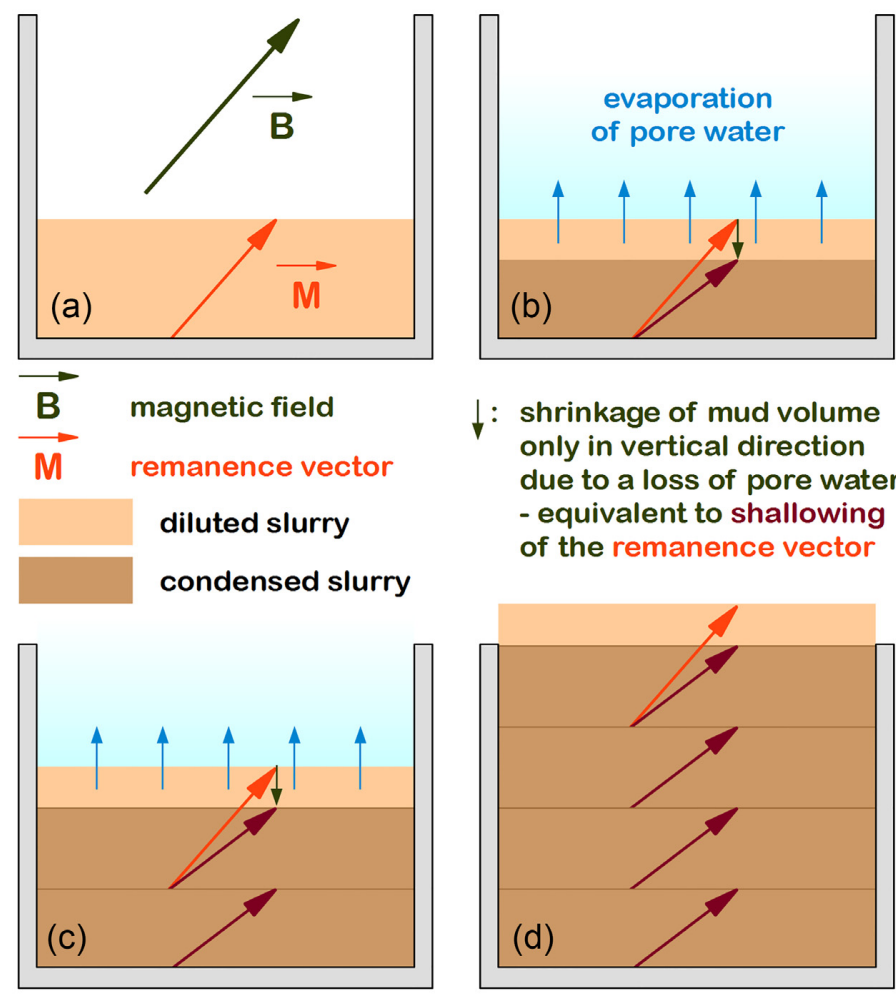

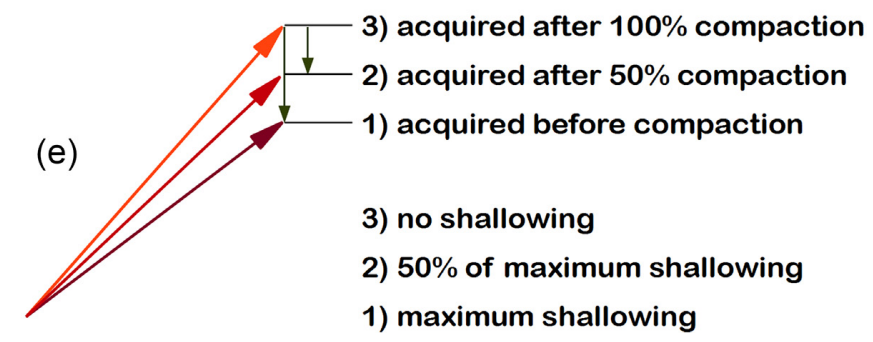

Figure 8. Simple concept for inclination shallowing during the experiments. (a) Injection of slurry and immediate alignment of magnetic particles parallel to the ambient magnetic field $\mathbf{B}$, forming the magnetization vector $\mathbf{M}$ (light red arrow). (b) Due to evaporation (blue upward directed arrows) the diluted slurry (light brown) gets condensed in vertical direction (dark brown), shallowing the locked-in magnetization vector (dark red arrow). (c) Injection of a second layer with subsequent evaporation and shallowing the magnetization direction like in layer one. (d) Final situation after injection of four layers. (e) Theoretical magnetization vector with (1) remanence acquisition before compaction and maximum shallowing, (2) remanence acquisition after 50 per cent compaction and 50 per cent of maximum shallowing, and (3) remanence acquisition after compaction without inclination shallowing.

$\left(\kappa_{\mathrm{LF}}\right)$ and intensity of saturation magnetization (SIRM) are shown in Fig. 11 (vibrating platform) and Fig. 12 (still platform). Slopes of linear fits to ARM-normalized data are similar, with 0.83 both for normalization with ARM (50 $\mu \mathrm{T}$ static, $100 \mathrm{mT}$ AF; Fig. 11c) and sARM (150 $\mu \mathrm{T}$ static, $100 \mathrm{mT}$ AF; Fig. 11d) from samples deposited on vibrating platform, and 0.82 from samples on still platform (Fig. 12c). Thus, there is no difference in the results from both methods (ARM and sARM). However, it is interesting that the slope (DRM/ARM) at $50 \mu \mathrm{T}$ is around 3. This indicates that the DRM acquired in a field of $50 \mu \mathrm{T}$ is three times higher than the ARM acquired in a static field of $50 \mu \mathrm{T}$ and $100 \mathrm{mT}$ AF amplitude. This points towards a high efficiency in DRM acquisition with the chosen material and experimental conditions. A similar relationship is valid for the sARM acquired with a static field of $150 \mu \mathrm{T}$, when extrapolating data (Fig. 11d). Actually, according to Liu et al. (2020), NRM/ARM slopes from natural Black Sea sediments are only in the range from 0.03 to 0.73 according to estimated field intensities of $2.8 \mu \mathrm{T}$ during the Laschamps excursion and $60 \mu \mathrm{T}$ at $\sim 50 \mathrm{ka}$, respectively (red dashed lines in Figs $11 \mathrm{c}, \mathrm{d}$ and 12c). Thus, the laboratory acquired magnetization is about five times more efficient than the NRM of studied Black Sea sediments. A similar observation was also done by King (1955) who found that redeposited sediments from Sweden carried a magnetization 3-4.5 times higher than the original NRM. The most plausible explanation is, that the extremely calm conditions in the laboratory are more favourite for a good alignment of the magnetic particles than natural conditions with, for example moving bottom water King (1955).

All ARM-normalized data, like the absolute DRM intensities (Fig. 10), point to a slight non-linear behaviour in DRM acquisition. Slopes of linear fits to estimates of rPI based on normalization by $\kappa_{\mathrm{LF}}(0.83)$ and SIRM intensity ( 0.82$)$ confirm the ARM-based results, at least for samples deposited on vibrating platform (Fig. 11). Slopes for $\kappa_{\mathrm{LF}}$-normalized (0.79) and SIRM-normalized (0.78) rPI 
vibrating platform

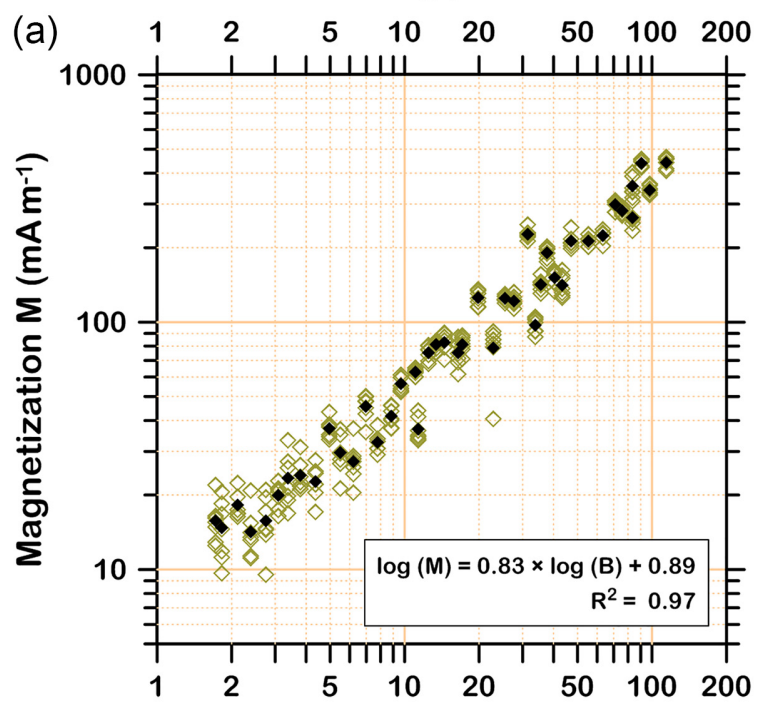

(b)

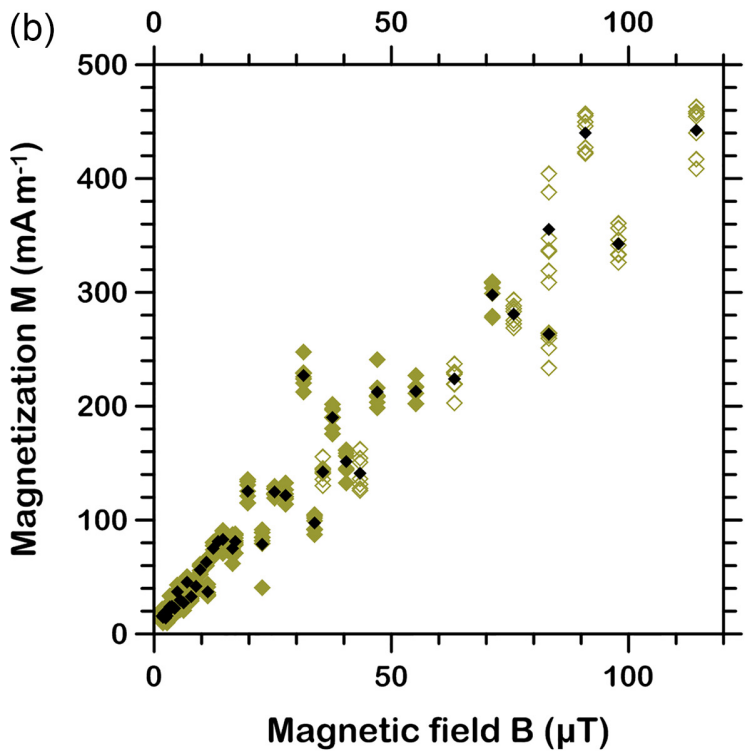

still platform
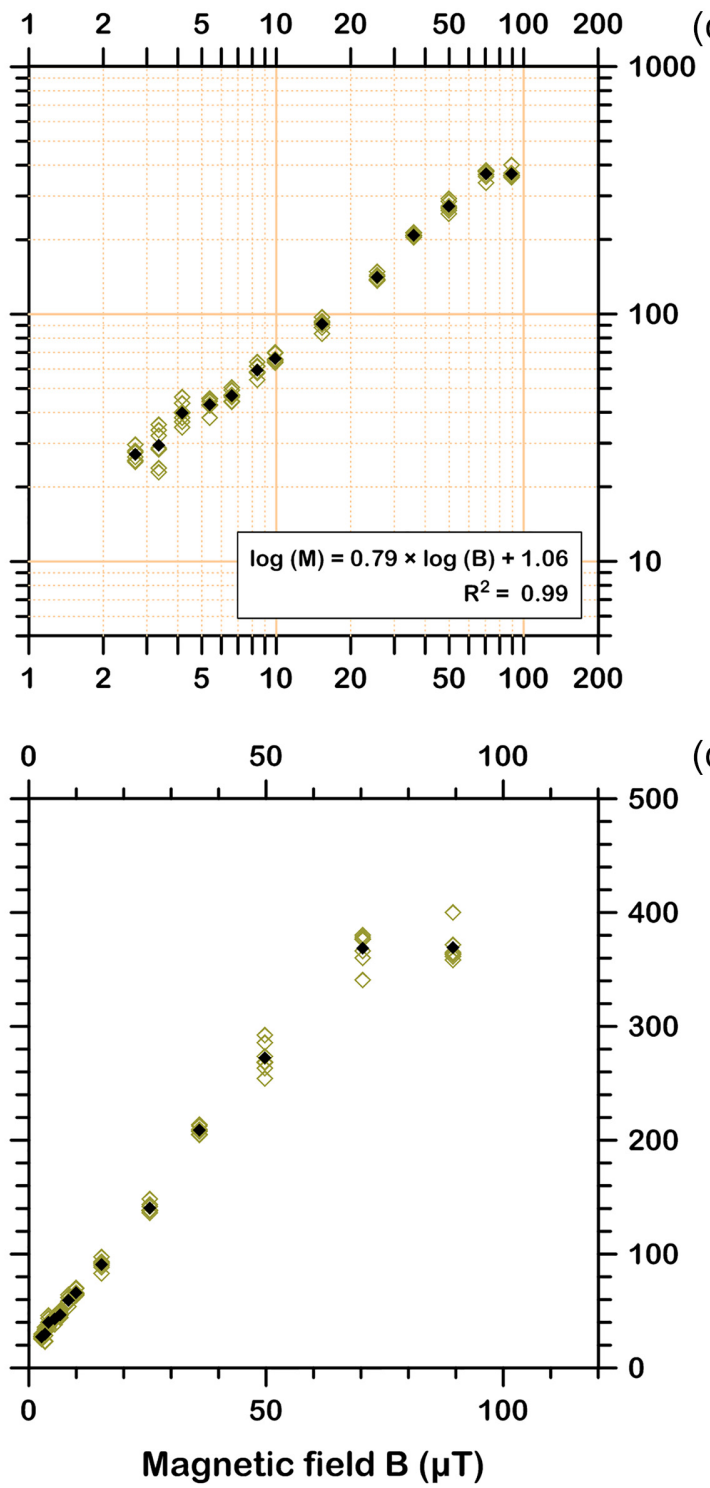

Figure 9. Acquired DRM intensities of all investigated samples versus magnetic field during deposition of the sediments. Open green diamonds mark individual samples whereas black closed diamonds represent the mean values of seven samples deposited at the same field intensity. Left (right) DRMs acquired on a vibrating (still) platform. In the linear (logarithmic) plots scatter is larger for samples deposited at higher (lower) fields. A statistical analysis of the field dependence of the mean DRM values is given in the insets. Since variable amounts of slurry (see Tables 1-3) were injected into the sample boxes, DRM intensities were normalized to a common volume of $11 \mathrm{~cm}^{3}$.

estimates from samples deposited on still platform (Figs 12a and b) point towards a slightly more non-linear behaviour when using these parameter ratios, though the differences are not large.

\section{DISCUSSION}

One major aspect of this study was to find a simple way to produce a large number of mechanically stable and measurable samples deposited in a wide range of field settings in an appropriate amount of time. Dewatering diluted slurries by mechanical compaction appeared to be too impractical needing a much more complicated experimental setup and much more working steps. Theoretically, it also bears the danger of distorting the samples' fabric when squeezing is performed too fast. Compaction by simply letting a sufficient amount of pore water slowly evaporate, therefore, appeared to be a better alternative, keeping the sediments untouched after deposition. When you come to think of it, the air pressure of 1 bar is equal to $1 \mathrm{~kg} \mathrm{~cm}^{-2}$. Since the sample boxes' open sides are $4 \mathrm{~cm}^{2}$, the atmosphere was pressing with a weight of $4 \mathrm{~kg}$ permanently on the slurry. Obtained condensed samples with a density of 1.45-1.55 were still humid and had a pasty consistency and a magnetic fabric similar to natural samples from the Black Sea with a degree of anisotropy between 4 and 8 per cent (Fig. 6). This is an indication that the produced samples have a magnetic fabric similar to the natural samples.

The most astonishing result of the performed experiments is that the vibration, intended to force compaction of the bulk sediment and/or promote the alignment of magnetic particles inside the initially $1.3 \mathrm{~g} \mathrm{~cm}^{-3}$ dense slurry, did not have any clear influence. Obviously, already the initial manual shaking of the sample holder, 


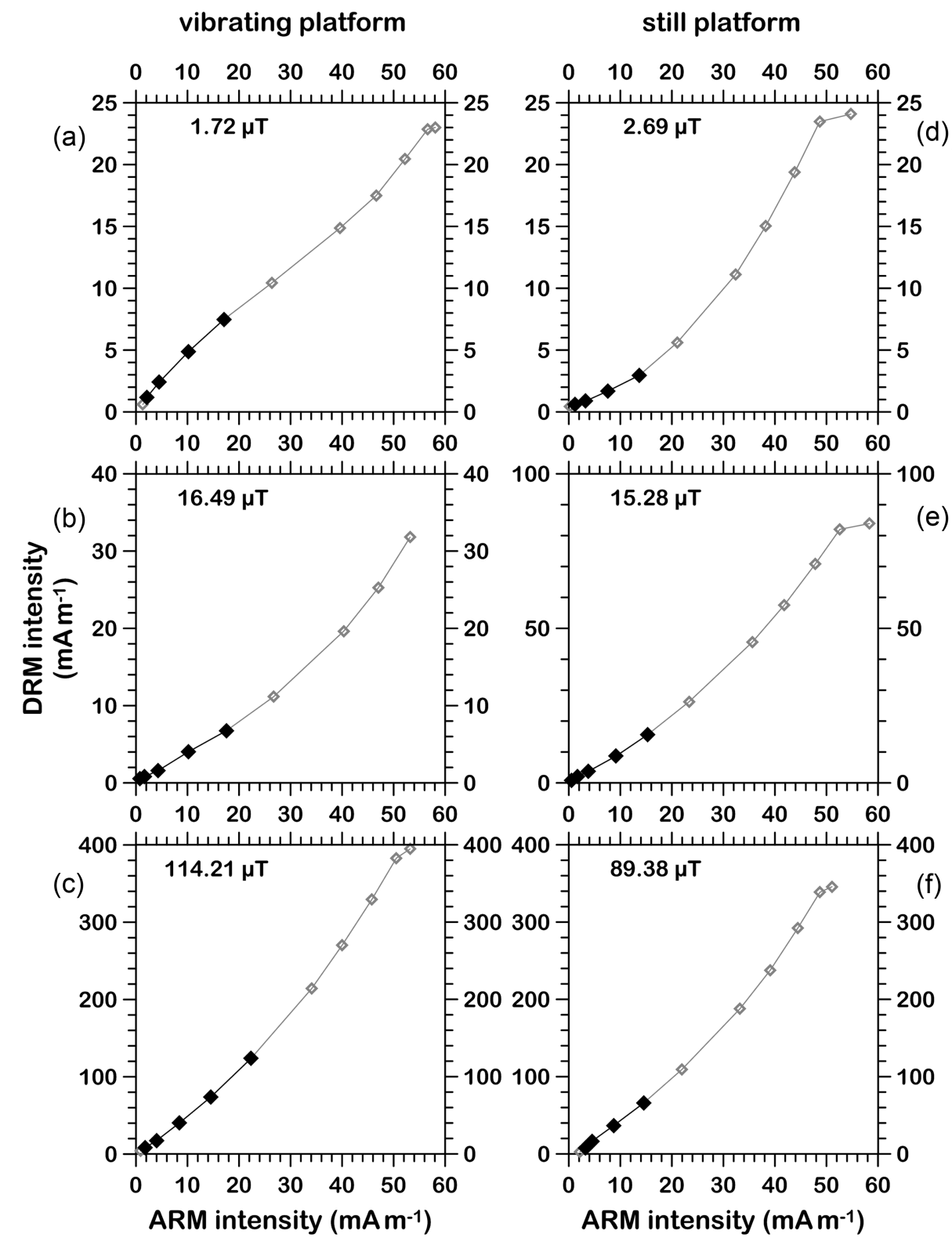

Figure 10. Plots of DRM intensity versus ARM intensity in the course of AF demagnetization for the determination of relative palaeointensity as also performed for natural samples from the Black Sea. Left (right): samples produced with vibrating (still) platform. For determination of the slope only the steps marked in black, representing the most linear part of the track, were taken into account.

applied in order to equalize the slurry's surface after injection, either with vibrating or with still platform, was sufficient enough to activate the magnetic particles and fix them again sufficiently and with a degree of alignment that is proportional to the magnetic field set by the surrounding coils. In this context it might be interesting to note that the slurry in the reservoir beaker came to a sudden stop after being stirred instead of swirling around, when the mixer was turned off. This probably indicates an immediate development of a sedimentary/magnetic fabric able to resist against magnetic fields as applied in this study.

Though the relationship is not really linear (Figs 9, 11 and 12), even at the lowest fields of down to $1.72 \mu \mathrm{T}$ a magnetization intensity according to the experimental field was acquired. However, towards lower fields the intensities (and directions) became more scattered, likely due to the limited size of the experimental setup within an inhomogeneous ambient magnetic field. And, in all cases a clear inclination shallowing was observed. The latter is interpreted to be due to the strong compaction in vertical direction of 40 per cent and more, occurring during the relatively fast compaction of the slurry by evaporation, compared to a much slower compaction under natural conditions. Nevertheless, this indicates that the magnetization was acquired almost instantaneously, with a subsequent flattening in inclination by subsequent compaction in vertical direction (Fig. 8).

Since rPI estimates by normalization with ARM, $\kappa_{\mathrm{LF}}$, and SIRM yielded the same relationship with the test field, with a slope of 0.83 $\left(\mathbf{r P I} \sim \mathbf{B}^{0.83}\right)$, DRM intensities (Fig. 9) are used for the following discussion. The DRM intensities of all investigated samples, both with vibrating and still platform, are summarized in Fig. 13 (black diamonds). The line fitted to the data (olive straight line), with a slope of $0.82\left(\mathbf{M} \sim \mathbf{B}^{0.82}\right)$, is plotted together with theoretical fits. A slope of 1.10 (blue, short dashes) refers to the results of 


\section{vibrating platform}
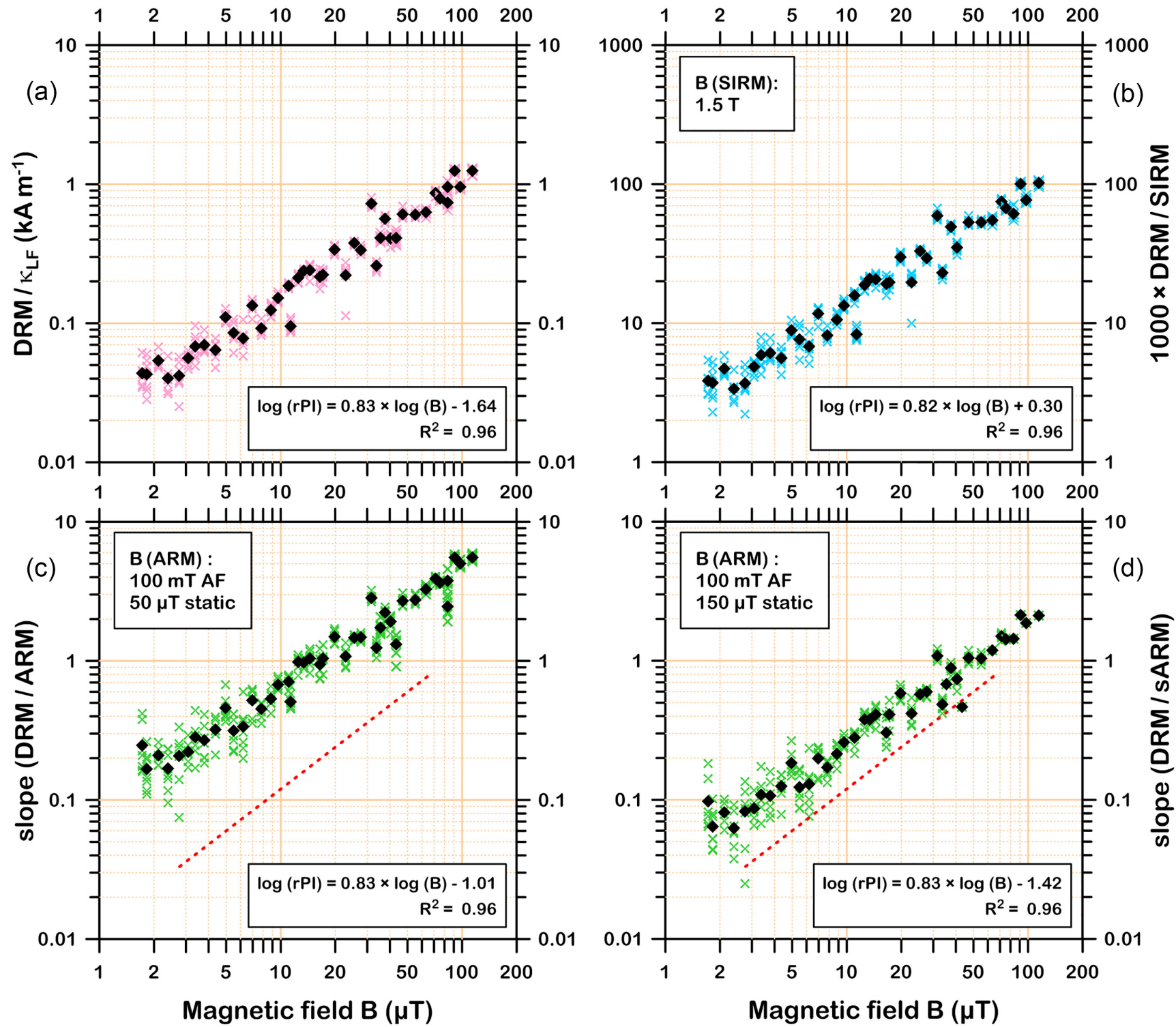

Figure 11. Common methods used to estimate the relative palaeointensity (rPI) from natural samples applied to the artificial samples of this study, produced with vibrating platform. DRM intensity normalized by (a) low-field volume susceptibility $\kappa_{\mathrm{LF}}$ and (b) saturation magnetization SIRM, acquired in a pulsed field of 1.5 T, slope of DRM intensity normalized by ARM intensity during alternating field (AF) demagnetization (comp. Fig. 9). Two different approximations were performed using (c) $50 \mu \mathrm{T}$ and (d) $150 \mu \mathrm{T}$ static field superimposed on an AF field of $100 \mathrm{mT}$. Coloured crosses mark individual samples whereas black closed diamonds represent the mean values of seven samples deposited at the same field intensity. A statistical analysis of the field dependence of the mean rPI values is given in the insets. In (c) and (d) the dotted red line marks the range of slope (NRM/ARM) versus estimated field intensity from natural samples (after Nowaczyk et al. 2013; Liu et al. 2020). The ARM of these samples were produced with $100 \mathrm{mT}$ AF and $50 \mu \mathrm{T}$ static field.

Kent (1973; comp. Fig. 1), a slope of 1.00 represents a strict linear relationship (dotted black line), and a slope of 0.70 (light orange, long dashes) was used by Gilder et al. (2019) to fit their experimental results from lacustrine sediment samples. However, they produced samples in fields between $300 \mu \mathrm{T}$ and $70 \mathrm{mT}$, thus not really fitting to the topic of this study. All data/fits are rescaled in a way that they intersect each other at a magnetization level of 1 (arb. unit) related to a field level of $35 \mu \mathrm{T}$ (global mid-range present-day field level). Although it should be clear from a mathematical point of view, it is pointed out here again that slopes of straight lines in a double-log plot different from 1 (see formulas 1 and 2) represent a non-linear behaviour. For example, a slope of 2 (3) represents a quadratic (cubic) relationship, and a slope of 0.5 represents a square-root relationship.

The majority of data obtained from redeposited Black Sea sediments originate from samples produced at field intensities lower than the minimum field values of the present-day field (about $23 \mu \mathrm{T}$, South Atlantic Anomaly, US/UK World Magnetic Model—Epoch 2020.0). The whole range of low field intensities estimated for the transitional field during the Laschamps excursion in the Black Sea area (down to $2.8 \mu \mathrm{T}$; after Liu et al. 2020) could be evenly covered with experimental data. Due to the chosen combination of power supply and coil design (compensation efficiency), a technical setup especially designed for the precise performance of low-field 


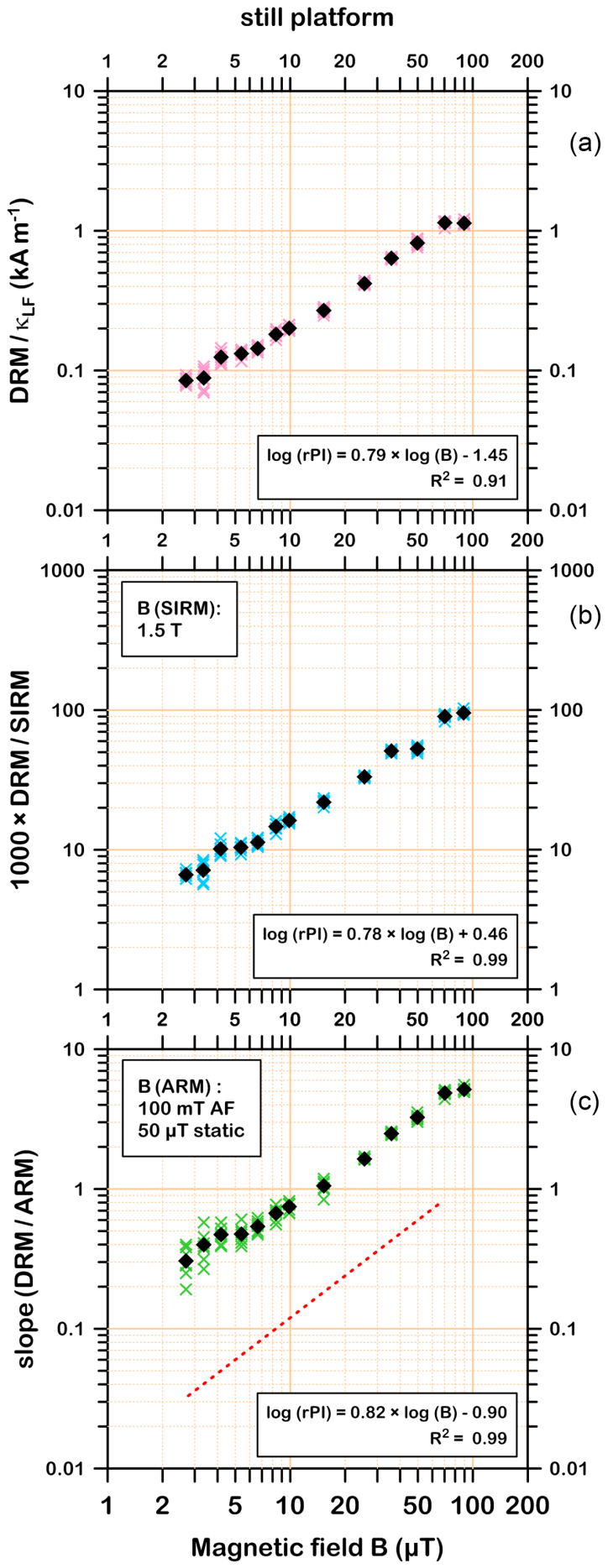

Figure 12. Common methods used to estimate the relative palaeointensity (rPI) from natural samples applied to the artificial samples of this study, produced with still platform. DRM intensity normalized by (a) volume susceptibility $\kappa_{\mathrm{LF}}$, (b) saturation magnetization SIRM, acquired in a pulsed field of $1.5 \mathrm{~T}$ and (c) slope of DRM intensity normalized by ARM intensity (50 $\mu \mathrm{T}$ static field, $100 \mathrm{mT} \mathrm{AF}$ ) during alternating field (AF) demagnetization (comp. Fig. 9). Coloured crosses mark individual samples whereas black closed diamonds represent the mean values of seven samples deposited at the same field intensity. A statistical analysis of the field dependence of the mean $\mathrm{rPI}$ values is given in the insets. In (c) the dotted red line marks the range of slope (NRM/ARM) versus estimated field intensity from natural samples (after Nowaczyk et al. 2013; Liu et al. 2020). The ARM of these samples were produced with $100 \mathrm{mT} \mathrm{AF}$ and $50 \mu \mathrm{T}$ static field. experiments, test fields above $115 \mu \mathrm{T}$ could not be realized. Thus, an expected flattening of the slope of acquired DRM versus high(er) magnetic fields, such as observed in the classical studies of, for example Johnson et al. (1948) and Barton et al. (1980), could not be checked for the investigated Black Sea sediments. Anyway, this was not a major goal of this study and obtained data are sufficient for interpretation. The limited homogeneity of the magnetic environment also did not allow to safely set fields lower than $1.7 \mu \mathrm{T}$. Thus it could not be checked whether there is a threshold level (minimum field intensity) under which no magnetization is acquired. Nevertheless, DRM acquisition across almost two orders of magnitude in field strength could be investigated, requiring a net time period of about 2 yr. The scatter observed in the obtained DRM distribution is interpreted as being due to the experimental conditions with a fairly dense slurry of $1.30-1.55 \mathrm{~g} \mathrm{~cm}^{-3}$ and the relatively short compaction time of 4-7 d (if at all relevant) achieved by a fairly fast condensing in order to sufficiently increase the rigidity of the slurry. This was necessary so that the samples could be rotated inside the Kappabridge for AMS determination, or the spinner magnetometer for SIRM acquisition experiments, without distorting the integrity of the samples.

One aspect of this study was to possibly find a direct calibration of the natural depositional remanent magnetization of Black Sea sediments by the performed redeposition experiments under controlled field conditions. But, obviously, concerning the acquired magnetization intensity, the chosen laboratory conditions were too ideal, as the measured intensities were systematically stronger than in the natural samples when normalized by ARM. At least the offset between the estimates of relative palaeointensity (slope (NRM/ARM)) from the natural samples (red dashed lines in Figs 11c and 12c) and the same type of estimates from the redeposited material is quite constant. The constant offset in the double-log plots of Figs 11c and $12 \mathrm{c}$ means that there is a constant factor of about five between magnetization intensities acquired in this study and estimated field intensities from natural samples. The latter were obtained by comparison of the Black Sea relative palaeointensity distribution to absolute palaeointensity data from the past $50 \mathrm{ka}$ (Nowaczyk et al 2013; Liu et al. 2020), assuming a linear relationship. A magnetization stronger than in natural samples was not expected. Since a fairly thick slurry was used, it was more expected, that towards lower fields the acquisition of magnetizations might be less effective, due to friction on the scale of pore space, or even inhibit an alignment at all. But, when compared to the results from natural samples with an assumed linear relationship between magnetization and magnetic field (red dashes lines in Figs 11c and 12c) the acquisition of magnetization seems to be relatively a bit more effective than at higher fields, though more scattered. Probably this scatter is due to interstitial friction, being more relevant for larger particles with a less fortunate ratio of magnetic moment to volume, due to the presence of more than one domain in the largest particles. Nevertheless, the almost constant offset (factor) between NRM/ARM of natural samples and artificial samples versus magnetic field during deposition indicates that (at least) one controlling factor counteracting the alignment of magnetic particles, which is independent of the magnetic field, was not encountered during the redeposition experiments. Natural glacial sediments in the SE Black Sea were built up with a deposition rate between 20 and $40 \mathrm{~cm} \mathrm{ka}^{-1}$ (Liu et al. 2020), or 0.2 to $0.4 \mathrm{~m} \mathrm{ma}^{-1}$, while during the experiments the slurry was deposited at a rate of about $800 \mathrm{~m} \mathrm{ma}^{-1}$ (15 $\mathrm{mm}$ per week), that is, two thousand times faster. Under natural conditions there is a transition from water, via loose sediment into sediments rigid enough 


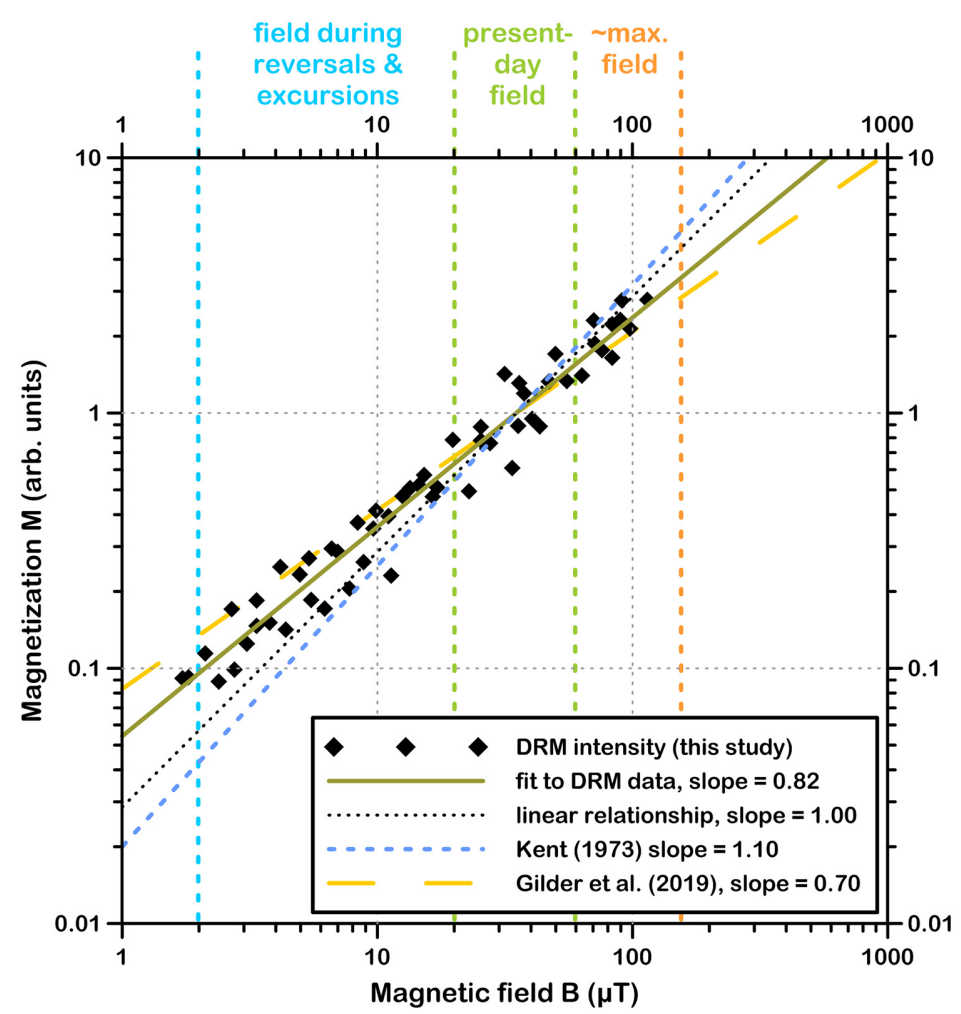

Figure 13. DRM intensities $\mathbf{M}$ from all investigated samples (vibrating and still platform) from this study versus magnetic field $\mathbf{B}$. For a better comparison, all data has been rescaled in a way that the fit (straight olive line) yields a magnetization of 1 (arb. units) at a median field of $35 \mu \mathrm{T}$. The dotted black line represents a strict linear behaviour (slope $=1.00$ ). The blue line with short dashes (slope $=1.10$ ) fits the experimental data between about 20 and $120 \mu \mathrm{T}$ of Kent (1973, comp. Fig. 1), whereas the orange line with long dashes (slope = 0.70) fits the data of Gilder et al. (2019), who investigated the field range from $300 \mu \mathrm{T}$ to $70 \mathrm{mT}$.

to fix magnetic particles aligned to the geomagnetic field permanently in space. Until this status is reached, for example seasonal currents, not too strong, probably with changing directions, could be one force counteracting the alignment by the magnetic field. This is something not occurring under (fast) laboratory conditions inside $2 \times 2 \mathrm{~cm}$ small boxes. Another reason might be Brownian motion of the water molecules in the upper loose natural sediments as a counteracting force. During the laboratory experiments Brownian motion might not play a major role since the slurry was fairly dense with a much higher ratio of (denser) siliciclastic particles with a high inertia to water (molecules), and also a much shorter impact time.

The constant factor between the slope (NRM/ARM) of the natural samples and slope (DRM/ARM) of the artificial samples should justify the interpretation that relative palaeointensities derived from the natural Black Sea sediments are not completely wrong. Instead they can be taken as a fairly realistic image of a highly dynamic geomagnetic field with field strength ratios of 24:1 during MIS 3 (50 ka versus $41 \mathrm{ka}$ ). In consequence it must be concluded that palaeointensity stacks having a much lower intensity ratio, such as, for example the PISO1500 (Channell et al. 2009) with a ratio of 4:1 (50 ka versus $41 \mathrm{ka}$ ), obviously represent a record significantly damped in amplitude. The reasons for such a low dynamic range might be an improper alignment of the individual records due to age models with an insufficient precision and/or a long-term remanence acquisition in the records included in the stack. The latter is supported by the fact that at least about half of the cores included in the GLOPIS-75 stack (Laj et al. 2004) do not show the Laschamps excursion in terms of pronounced directional deviations or even a full reversal (Nowaczyk et al. 2013).
This time-consuming study was aiming to check the relationship between geomagnetic field variations and acquired magnetization intensity in Black Sea sediments. Therefore, as far as possible, the amplitude of the test field was systematically changed, not its direction. A systematic analysis of the inclination shallowing, as observed in this study, should be investigated in the future. Inclination shallowing is also observed in the natural samples from the Black Sea (Liu et al. 2020). However, this does not disqualify the palaeomagnetic interpretation of natural samples, since the Laschamps excursion in its fully reversed phase exhibited steep negative inclinations in studied Black sea sediments, which in reality should have been even steeper. Since during the performed experiments the remanence was obviously quickly locked-in by the slurry with a density of $1.30 \mathrm{~g} \mathrm{~cm}^{-3}$ further experiments with variable slurry densities, at a reduced number of field settings, are also needed to approach (find out more) realistic conditions to simulate remanence acquisition in Black sea sediments.

\section{CONCLUSIONS}

Redeposition experiments using diluted slurry from the SE Black Sea yielded a constant, though slightly non-linear relationship between applied magnetic fields ranging form 1.72 to $114.21 \mu \mathrm{T}$ and acquired remanence intensities $\left(\mathbf{M} \sim \mathbf{B}^{0.82}\right)$. The compaction process of the sediments was simulated by letting the $1.30 \mathrm{~g} \mathrm{~cm}^{-3}$ dense slurry condense by pore water evaporation over 4-7 d with the majority of samples kept on a vibrating platform. Vibration was intended to support both compaction of the slurry and alignment 
of magnetic particles inside the fairly thick slurry. But, it turned out that vibration did not have any effect on the used Black Sea sediments. The magnetic fabric of the artificially produced samples resemble results obtained from natural samples from the Black Sea. Both analysis of results from AF demagnetization and observed inclination shallowing of the acquired magnetization suggest that the produced DRM was locked-in fairly quickly, if not even instantaneously. The obtained results strongly support the interpretation of magnetostratigraphic results obtained from SE Black Sea sediments that the Laschamps excursion at $41 \mathrm{ka}$ was partly associated with field intensities as low as $2.8 \mu \mathrm{T}$.

\section{ACKNOWLEDGEMENTS}

The author would like to thank S. Mayanna and I. Schäpan for technical help with SEM imaging. J. Liu helped during construction of the coil system. Two anonymous reviewers are thanked for their constructive suggestions for improving the manuscript. Data from Figures 9, 11, and 12 are available via: GFZ Data Services (Nowaczyk 2020).

\section{REFERENCES}

Barton, C.E., McElhinny, M.W. \& Edwards, D.J., 1980. Laboratory studies of depositional DRM, Geophys. J. R. astr. Soc., 61, 355-377.

Blow, R.A. \& Hamilton, N., 1978. Effect of compaction on the acquisition of a detrital remanent magnetization in fine-grained sediments, Geophys. J. R. astr. Soc., 52, 13-23.

Bonhommet, N. \& Babkine, J., 1967. Sur la présence d'aimantation inversée dans la Chaîne des Puys, C.R. Acad. Sc. Paris, 264, 92-94.

Channell, J.E.T., Xuan, C. \& Hodell, D.A., 2009. Stacking paleointensity and oxygen isotope data for the last 1.5 Myr (PISO-1500), Earth planet. Sci. Lett., 283, 14-23.

Gilder, S.A., He, K., Wack, M. \& Ježek, J., 2019. Relative paleointensity estimates from magnetic anisotropy: proof of concept, Earth planet. Sci. Lett., 519, 83-91.

Gillot, P.Y., Labeyrie, J., Laj, C., Valladas, G., Guèrin, G., Poupeau, G. \& Delibrias, G., 1979. Age of the Laschamp paleomagnetic excursion revisited, Earth planet. Sci. Lett., 42, 444-450.

Guillou, H., Singer, B.S., Laj, C., Kissel, C., Scaillet, S. \& Jicha, B.R., 2004. On the age of the Laschamp excursion, Earth planet. Sci. Lett., 227, 331-343.

Irving, E. \& Major, A., 1964. Post-depositional detrital remanent magnetization in a synthetic sediment, Sedimentology, 3, 135-143.

Johnson, E.A., Murphy, T. \& Torreson, O.W., 1948. Pre-history of the Earth's magnetic field, Terr. Magn. Atmos. Electr., 53(4), 349-372.

Katari, K. \& Tauxe, L., 2000. Effects of $\mathrm{pH}$ and salinity on the intensity of magnetization in redeposited sediments, Earth planet. Sci. Lett., 181, 489-496.

Katari, K., Tauxe, L. \& King, J., 2000. A reassessment of post-depositional remanent magnetism: preliminary experiments with natural sediments, Earth planet. Sci. Lett., 183, 147-160.

Kent, D.V., 1973. Post-depositional remanent magnetization in deep-sea sediment, Nature, 246, 32-34.

King, R.F., 1955. The remanent magnetism of artificially deposited sediments, Geophys. Suppl. MNRAS, 7(3), 115-134.

Kirschvink, J.L., 1980. The least-squares line and plane and the analysis of palaeomagnetic data, Geophys. J. R. astr. Soc., 62, 699-718.

Kornprobst, J. \& Lénat, J.-F., 2019. Changing name for Earth's changing poles, EOS, Trans. Am. geophys. Un., 100, doi:10.1029/2019EO117913.

Laj, C., Kissel, C. \& Beer, J., 2004. High resolution global paleointensity stack since $75 \mathrm{kyr}$ (GLOPIS-75) calibrated to absolute values, in Timescales of the Paleomagnetic Field, Geophys. Monogr., Vol. 145, pp. 255-265, Channell, J.E.T., Kent, D.V., Lowrie, W. \& Meert, J.G., eds. Am. Geophys. Union.
Liu, J., Nowaczyk, N.R., Frank, U. \& Arz, H.W., 2018. A 20-15 ka highresolution paleomagnetic secular variation record from Black Sea sediments - no evidence for the 'Hilina Pali' excursion, Earth planet. Sci. Lett., 492, 174-185.

Liu, J., Nowaczyk, N.R., Frank, U. \& Arz, H.W., 2019. Geomagnetic paleosecular variation record spanning from 40 to $20 \mathrm{ka}$-implications for the Mono Lake excursion from Black Sea sediments, Earth planet. Sci. Lett., 509, 114-124.

Liu, J., Nowaczyk, N.R., Panovska, S., Korte, M. \& Arz, H.W., 2020. The Norwegian-Greenland Sea, the Laschamps and the Mono Lake excursions recorded in a Black Sea sedimentary sequence spanning from 68.9 to 14.5 ka. J. geophys. Res., 125, e2019JB019225, doi:10.1029/2019JB019225.

Løvlie, R., 1976. The intensity pattern of post-depositional remanence acquired in some marine sediments deposited during a reversal of the external magnetic field, Earth planet. Sci. Lett., 30, 209-214.

Nowaczyk, N.R., 2011. Dissolution of titanomagnetite and sulphidization in sediments from Lake Kinneret, Israel, Geophys. J. Int., 187, 34-44.

Nowaczyk, N.R., Arz, H.W., Frank, U., Kind, J. \& Plessen, B., 2012. Dynamics of the Laschamp geomagnetic excursion from Black Sea sediments, Earth planet. Sci. Lett., 351-352, 54-69.

Nowaczyk, N.R., Frank, U., Kind, J. \& Arz, H.W., 2013. A high-resolution paleointensity stack of the past 14 to $68 \mathrm{ka}$ from Black Sea sediments, Earth planet. Sci. Lett., 384, 1-16.

Nowaczyk, N.R., Liu, J., Frank, U. \& Arz, H.W., 2018. A high-resolution paleosecular variation record from Black Sea sediments indicating fast directional changes associated with low field intensities during marine isotope stage (MIS) 4, Earth planet. Sci. Lett., 484, 15-29.

Nowaczyk, N.R., Liu, J., Plessen, B., Wegwerth, A. \& Arz, H.W., in prepration. A high-resolution paleosecular variation record for marine isotope stage 6 from SE Black Sea sediments.

Nowaczyk, N., 2020. Data from redeposition experiments of glacial Black Sea sediments, GFZ Data Services, https://doi.org/10.5880/GFZ.4.3.2020.001.

Otofuji, Y \& Sasajima, S., 1981. A magnetization process of sediments: laboratory experiments on post-depositional remanent magnetization, Geophys. J. R. astr. Soc., 66, 241-259.

Plenier, G., Valet, J.-P., Guérin, G., Lefèvre, J.-C., LeGoff, M. \& CarterStiglitz, B., 2007. Origin and age of the directions recorded during the Laschamp event in the Chaîne des Puys, Earth planet. Sci. Lett., 259, 414-431.

Shaar, R. et al., 2018. The First catalog of archaeomagnetic directions from Israel with 4,000 years of geomagnetic secular variations, Front. Earth Sci., 6, 164, doi:10.3389/feart.2018.00164.

Skinner, B.J., Erd, R.C. \& Grimaldi, F.S., 1964. Greigite, the thiospinel of iron; a new mineral. Am. Mineral., 49, 543-555.

Tauxe, L., 1993. Sedimentary records of relative paleointensity of the geomagnetic field: theory and practice, Rev. Geophys., 31(3), 319-354.

Tauxe, L. \& Kent, D.V., 1984. Properties of a detrital remanence carried by haematite from study of modern river deposits and laboratory redeposition experiments, Geophys. J. R. astr. Soc., 77, 543-561.

Tucker, P., 1980. Stirred remanent magnetization: a laboratory analogue of post-depositional realignment. $J$ Geophys., 48, 153-157.

Tucker, P., 1981. Palaeointensities from sediments: normalization by laboratory redepositions. Earth planet. Sci. Lett., 56, 398-404.

van Vreumingen, M.J., 1993a. The magnetization intensity of some artificial suspensions while flocculating in a magnetic field, Geophys. J. Int., 114, 601-606.

van Vreumingen, M.J., 1993b. The influence of salinity and flocculation upon the acquisition of remanent magnetization in some artificial sediments, Geophys. J. Int., 114, 607-614.

Wegwerth, A., Dellwig, O., Wulf, S., Plessen, B., Kleinhanns, I.C., Nowaczyk, N.R., Liu, J. \& Arz, H.W, 2019. Major hydrological shifts in the Black Sea "Lake" in response to ice sheet collapses during MIS 6 (130e184 ka BP), Quat. Sci. Rev., 219, 126-144.

Yoshida, S. \& Katsura, I., 1985. Characterization of fine magnetic grains in sediments by the suspension method, Geophys. J. R. astr. Soc., 82, 301-317. 


\section{SUPPORTING INFORMATION}

Supplementary data are available at $G J I$ online.

Figure S1. Initial setup of resedimentation experiment with a large solenoid for producing a vertically oriented field. After setting the field with the help of a tri-axial fluxgate magnetometer (a) a square plastic tube filled with water and a holder with four sample boxes fixed to its lower end was inserted into the solenoid (b). Then a sequence of injections with diluted slurry was started.

Figure S2. Initial procedure of resedimentation experiment with a large solenoid for producing a vertically oriented field: (a) setting the field, (b) first injection of diluted slurry, (c) injected slurry dispersed in water, (d) slurry settling into sample boxes and (e) next injection of slurry. Steps (b)-(e) were repeated 15-20 times over several weeks.

Figure S3. Coordinate system defined for calculation of the compensation capabilities of new coils for field control during resedimentation experiments (see next figures). The magnetic field $\mathrm{B}$ is mainly produced along the $Z$-axis, perpendicular to the coils' plane. Calculations of the vector components of the magnetic field $\mathrm{B}$ were performed along the main axes $X, Y$ and $Z$. I - (direction of) electric current, $L_{X}$ and $L_{Y}$-dimension of the coils, $d_{Z}$ - spacing of the coil pair.

Figure S4. Results from theoretical calculations of the compensation capabilities of the coils. Calculations of the main magnetic field vector component $\mathrm{B}_{Z}$ (perpendicular to the coils' plane) were performed along the main axes $X, Y$ and $Z$. (see Fig. S3). The horizontal dashed lines mark the range of a compensation down to 1 per cent and better. $L_{X}$ and $L_{Y}$ - dimension of the coils, $d_{Z}$ - spacing of the coil pair.

Figure S5. Results from theoretical calculations of the compensation capabilities of the coils. Same as Fig. S4, but zoomed into the compensation volume of 1 per cent and better, and the relation of the coil pairs' individual coordinate systems to the geographic coordinates. Calculations of the main magnetic field vector component $B_{\mathrm{Z}}$ (perpendicular to the coils' plane) were performed along the main axes $X, Y$ and $Z$ of the coil pairs' coordinate systems. Here the horizontal dashed lines mark the range of a compensation down to $1 \%$ and better.

Figure S6. Simplified wiring diagram of the coil compensation system finally built. A single power supply and a high-power potentiometer $(60 \mathrm{~W})$ for splitting the electric current is used to feed the coils. $N$-number of turns per coil, $L_{X}$ and $L_{Y}$-dimension of the coils, $d_{Z}$ - spacing of the coil pairs, $R$ - electric resistance, $f$ - field factor, $B_{V}$ and $B_{H}$ - field components to be compensated in Potsdam in vertical $(V)$ and horizontal $(H)$ direction, $I_{\text {comp }}$-electric current to achieve a complete field compensation.

Figure S7. Simplified perspective view of the coil assemblage used for resedimentation experiments. A wooden platform is held in position by strings which in turn are held by springs mounted to the coils' frame. The NS-compensating coils are vertically elongated in order to produce a larger (but less homogeneous) compensation volume. For the same reason, the coils compensating the vertical component have a spacing wider than for an optimal homogeneity (see Figs S4 and S5).

Figure S8. Tests for evaporation with diluted slurry with a density of $\sim 1.35 \mathrm{~g} \mathrm{~cm}^{-3}$ filled into $6 \mathrm{~cm}^{3}$ big plastic boxes. Curves in (a) with open symbols represent test with boxes permanently kept open while curves with closed symbols represent experiments with boxes kept under a large plastic box held up by empty boxes in order to enable some ventilation from the side. A detailed evaporation monitoring is shown in the inset (b). Typically, about $1.0 \mathrm{~g}(0.5 \mathrm{~g})$ of water evapourated during $24 \mathrm{hr}$ through the surface of the slurry [4 $\left.\mathrm{cm}^{2}\right]$ of the open (protected) box.

Figure S9. Relative frequency of rock magnetic parameter ratios determined on all investigated samples, illustrating the high homogeneity of the slurry used for the experiments. ARM - anhysteretic remanent magnetization, $\kappa(\mathrm{ARM})$-anhysteretic sysceptibility (ARM intensity normalized by applied static field of $50 \mu \mathrm{T}$ ), $\kappa_{\mathrm{LF}}$ - low-field susceptibility, SIRM - saturated iso-thermal remanent magnetization.

Please note: Oxford University Press is not responsible for the content or functionality of any supporting materials supplied by the authors. Any queries (other than missing material) should be directed to the corresponding author for the paper. 